\title{
Toward a Consensus on Applying Quantitative Liquid Chromatography-Tandem Mass Spectrometry Proteomics in Translational Pharmacology Research: A White Paper
}

Bhagwat Prasad $^{1, \dagger}$, Brahim Achour ${ }^{2, \dagger}$, Per Artursson ${ }^{3}$, Cornelis E.C.A. Hop ${ }^{4}$, Yurong Lai ${ }^{5}$, Philip C. Smith ${ }^{6}$, Jill Barber ${ }^{2}$, Jacek R. Wisniewski ${ }^{7}$, Daniel Spellman ${ }^{8}$, Yasuo Uchida ${ }^{9}$, Michael A. Zientek ${ }^{10}$, Jashvant D. Unadkat $^{1, *}$ and Amin Rostami-Hodjegan ${ }^{2,11, *}$

Quantitative translation of information on drug absorption, disposition, receptor engagement, and drug-drug interactions from bench to bedside requires models informed by physiological parameters that link in vitro studies to in vivo outcomes. To predict in vivo outcomes, biochemical data from experimental systems are routinely scaled using protein quantity in these systems and relevant tissues. Although several laboratories have generated useful quantitative proteomic data using state-of-the-art mass spectrometry, no harmonized guidelines exit for sample analysis and data integration to in vivo translation practices. To address this gap, a workshop was held on September 27 and 28, 2018, in Cambridge, MA, with 100 experts attending from academia, the pharmaceutical industry, and regulators. Various aspects of quantitative proteomics and its applications in translational pharmacology were debated. A summary of discussions and best practices identified by this expert panel are presented in this "White Paper" alongside unresolved issues that were outlined for future debates.

Quantitative translation of information on drug pharmacokinetics (PK) and pharmacodynamics (PD) requires models informed by data on physiological parameters that link in vitro studies to in vivo outcomes. These include the concentration of proteins in relevant tissues as well as experimental systems used for laboratory investigations. Owing to lack of specific substrates and optimized activity assays, activity is routinely measured in recombinant systems or cell lines and scaled up to in vivo predictions using abundance data. Scientists engaged in drug discovery and development are familiar with principles guiding in vitro-in vivo extrapolation (IVIVE) of drug absorption, distribution, metabolism, and excretion (ADME), drug-drug interactions (DDI), quantitative systems pharmacology (QSP), and quantitative system toxicology. However, with expansion of these activities and positive views by regulatory agencies, ${ }^{1}$ the importance of abundance data for these initiatives is becoming much more widely recognized.

A significant obstacle to quantification of ADME and PD target proteins is that conventional methods (e.g., Western blotting) are not always applicable as antibodies and purified standards for these proteins (e.g., transporters and receptors) are frequently not available. Moreover, these conventional methods lack specificity, are low throughput, and can be cumbersome. Different variants of the same protein, due to single nucleotide polymorphisms (SNPs) or posttranslational modifications (PTMs), present another challenge to conventional methods and necessitate the use of analytical techniques capable of detecting changes in a single amino acid. Hence, the introduction of liquid chromatography-tandem mass spectrometry (LC-MS/MS)-based quantitative proteomics has overcome several disadvantages associated with previous techniques. The high resolution and mass accuracy afforded by stateof-the-art proteomic techniques allow quantitative elucidation of SNPs and PTMs in biological samples using targeted and global analyses. Quantitative proteomics also allows quantification of multiple proteins simultaneously in a sample. The global, hypothesis-independent analysis of proteomes is a powerful approach in QSP research to identify pathways associated with drug PK and $\mathrm{PD}$, as well as disease-related perturbations, which in turn are critical for better dose-response prediction.

Despite routine application of quantitative proteomics and its integration in translational modeling in certain areas, including prediction of clearance, ${ }^{2-6} \mathrm{DDI},{ }^{7}$ and effects of covariates, such as age, ${ }^{8-11}$ disease, ${ }^{12,13}$ ethnicity, ${ }^{14,15}$ and genetics, ${ }^{9,14,16}$ lack of

\footnotetext{
${ }^{1}$ Department of Pharmaceutics, University of Washington, Seattle, Washington, USA; ${ }^{2}$ Centre for Applied Pharmacokinetic Research, University of Manchester, Manchester, UK; ${ }^{3}$ Department of Pharmacy, Uppsala University, Uppsala, Sweden; ${ }^{4}$ Genentech, South San Francisco, California, USA; ${ }^{5}$ Gilead Sciences, Foster City, California, USA; ${ }^{6}$ Eshelman School of Pharmacy, University of North Carolina at Chapel Hill, Chapel Hill, North Carolina, USA; ${ }^{7}$ Biochemical Proteomics Group, Max Planck Institute of Biochemistry, Martinsried, Germany; ${ }^{8}$ Pharmacokinetics Pharmacodynamics \& Drug Metabolism, Merck \& Co., Inc., West Point, Pennsylvania, USA; ${ }^{9}$ Graduate School of Pharmaceutical Sciences, Tohoku University, Sendai, Japan; ${ }^{10}$ Takeda California, San Diego, California, USA; ${ }^{11}$ Certara (Simcyp Division), Sheffield, UK. *Correspondence: Jashvant D. Unadkat (jash@uw.edu) and Amin Rostami-Hodjegan (amin.rostami@manchester.ac.uk)

†Joint first authors.
}

Received March 26, 2019; accepted May 22, 2019. doi:10.1002/cpt.1537 
harmonized practices in the implementation of the technique (and, hence, variability in reported abundances of the same proteins ${ }^{17}$ ) has led to some uncertainty in the outcomes of such applications, especially when there are insufficient clinical data for verification of predictions. Some variability can be due to differences in sample matrices used (e.g., cell lysates vs. membrane fractions), whereas other differences are potentially related to the measurement technique (e.g., targeted vs. global proteomics). These differences tend to propagate into discrepancies in predicted drug $\mathrm{PK}^{17}$

The appropriate use of internal and external controls to address technical variability has not been uniform in published reports, and there are unreported assumptions that not only require transparent declaration but also robust justification. For instance, most current LC-MS/MS methods rely on quantification of one or more proteotypic peptide(s) of the target protein, and, therefore, quantification assumes proteins are completely recovered from tissue and digested to peptides stoichiometrically. ${ }^{18}$ Furthermore, for unbiased quantification, peptide(s) need to be carefully selected for optimal ionization and detectability. ${ }^{19}$ Differences in sample extraction efficiency from in vitro systems (e.g., cell lines) and tissues can contribute significant technical variability. In addition, inadequately optimized and validated analytical methods represent another key source of variability.

To address these challenges, individual laboratories have recently implemented significant optimization efforts, including systematic interlaboratory studies and the use of different sample preparation methods, instrumentation, and data acquisition approaches. ${ }^{17}$ However, a concerted effort and a consensus on best practices among users of quantitative proteomics in drug discovery and development is still lacking. Therefore, a workshop involving scientists from academia, the pharmaceutical industry, and regulatory agencies was organized in Cambridge, MA, under the auspices of the International Society for the Study of Xenobiotics on September 27 and 28, 2018, to address these gaps. The salient objective of the workshop was to bring key opinion leaders and current and future users of quantitative proteomics to share their experiences and viewpoints and to debate various aspects of quantitative proteomic techniques with respect to sample preparation, data analysis, and applications. The major questions discussed in the workshop aimed to gather independent observations from participants into a consolidated viewpoint by the community.

1. Which techniques and approaches (e.g., global/targeted, relative/absolute, enriched fractions/cell lysates, and label-free/ label-based) are more suitable for specific ADME and PD applications?

2. Are enriched fractions essential or can tissue/cell homogenate be used for protein quantification?

3. What are the assumptions in using enriched fractions vs. tissue/cell homogenates?

4. Is "absolute quantification" necessary or can "relative quantification" be used for certain applications?

5. What quality controls are necessary for accurate and precise quantification of proteins?

6. If and how should protein abundance data be normalized?

7. What are the best practices in applying proteomics data for in vivo translation?
8. What are best practices for data sharing and which information should be reported in manuscripts?

This White Paper distills the discussions related to the above questions with a view to developing guidelines toward harmonization of quantitative proteomics in translational pharmacology research. Various unresolved topics have also been outlined for future discussions and potential resolution in subsequent workshops. The report presents the main discussion points arranged based on the workshop breakout sessions on the basic proteomic workflow from sample preparation to proteomic techniques, followed by data analysis and reporting, and finally applications of proteomic data in translational pharmacology research. Recommendations for best practices in sample preparation, proteomic measurement techniques, and data reporting are included in each section.

\section{BASIC PROTEOMICS WORKFLOW}

A basic proteomics workflow is shown in Figure $\mathbf{1}$ and recommended definitions of terms and techniques are proposed in Table S1. Most ADME proteins (such as CYPs, UGTs, and transporters) are membrane bound and of low abundance, and, therefore, specific considerations have to be made for accurate and reproducible quantification to be achieved. These include selection of suitable peptides and the use of techniques with a wide dynamic range and low limit of quantification (LLOQ).

Biological samples used in ADME and PD applications include tissues, cell lysates, microsomes, cytosol, S9, membrane extracts, biological fluids, and recombinant systems. Sample protein is digested using proteases, such as trypsin, $\mathrm{Lys} \mathrm{C}$, chymotrypsin, or a combination of proteases, which is followed by desalting and peptide enrichment before analysis. Proteomic quantification involves liquid chromatography (LC) separation and mass spectrometry (MS) analysis of proteotypic peptide(s) of a protein (i.e., peptide(s) not present in any other protein in a particular sample).$^{20}$ Peptide separation is achieved on nano-LC, micro-LC, or conventional-LC systems, which can be further improved using ion mobility separation prior to MS analysis. ${ }^{21,22}$ Analysis of precursor and product ions (mass filtering) can be achieved in space or in time depending on the mass analyzer. Selection of proteotypic peptides utilizes multiple in silico or experimental approaches and considers recommended criteria to ensure peptides are representative of target proteins (Table 1). Depending on the experiment, peptides can be selected before or after data acquisition. Multiple data acquisition and data analysis options are available. Both label-free and peptide labeling approaches are used to control experimental variables in LC separation and MS analysis. Open source or vendor-specific software is available for data analysis.

\section{SAMPLE PREPARATION APPROACHES}

Sample preparation invariably follows several defined steps (Figure 2a):

1. Collection of high quality cell/tissue samples

2. Selection of the tissue section(s) to be processed

3. Homogenization/lysis 


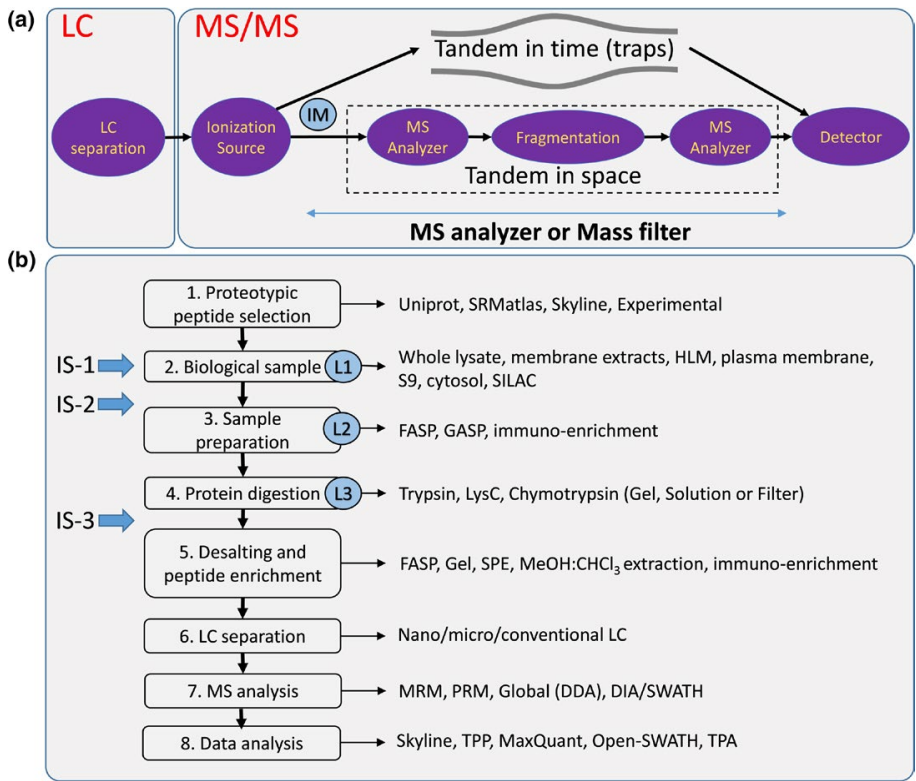

Figure 1 Basic LC-MS/MS quantitative analysis workflow. (a) Measurement of peptides in an LC-MS system. Additional separation such as ion mobility can also be added to the workflow to increase peptide resolution. (b) Various steps involved in LC-MS/MS analysis of peptides and associated proteomics techniques. Arrows denote steps where internal standards (or calibrators) can be introduced to address variability in sample processing, protease digestion, and matrix effect. Internal standards IS-1, IS-2, and IS-3 refer to SILAC protein/sample, QconCAT/PSAQ standards and heavy labeled peptide (AQUA) standards, respectively. Labeling of samples is carried out at different stages for SILAC (L1), ICAT (L2), and iTRAQ/TMT (L3). DDA, data-dependent acquisition; DIA, data-independent acquisition; FASP, filter-aided sample preparation; GASP, gel-aided sample preparation; HLM, human liver microsome; ICAT, isotope-coded affinity tagging; IM, ion mobility; IS $(1,2,3)$, internal standards; iTRAQ, isobaric tags for relative and absolute quantitation; L (1, 2, 3), label; LC, liquid chromatography; MRM, multiple-reaction monitoring; MS/MS, tandem mass spectrometry; PRM, parallel-reaction monitoring; PSAQ, protein standards for absolute quantification; QconCAT, quantitative concatemers; SILAC, stable-isotope labeling by amino acids in cell culture; SWATH, sequential window acquisition of all theoretical fragment mass spectra; TMT, tandem mass tags; TPA, total protein approach.

4. Preparation of fractions (not used for analysis of tissue/cell lysates)

5. Extraction of proteins

6. Denaturation/reduction/alkylation of proteins

7. Digestion and spiking of standards

8. "Desalting/cleaning" of digests before LC-MS analysis

All these steps are prone to technical variability and loss of analyte, and, therefore, appropriate quality controls (QCs) and recovery factors are required at several stages to correct for any losses incurred.

\section{Sample quality and characteristics}

Sample quality is an important factor and characteristics depend on pathological assessment, time from surgery to storage, and longterm storage conditions. The use of fresh, frozen, or formalin-fixed paraffin-embedded (FFPE) tissue requires different sample preparation considerations (particularly for homogenization) and can lead to differences in protein quantification. The use of fixed (e.g., FFPE) tissue is still considered particularly challenging; however, protocols for extraction and analysis of FFPE tissue at high protein recovery rates have previously been reported, ${ }^{23-25}$ with successful application to laser microdissected cells from human colon ${ }^{26}$ and breast ${ }^{27}$ samples.

In addition to tissue quality, the anatomic structure of the sample and tissue-specific characteristics are very important for downstream sample preparation. For example, in the kidneys, cortex preparations represent proximal tubules, whereas the medulla contains collecting tubules, which have different ADME protein expression patterns. ${ }^{28}$ In the intestine, region-specific expression of drug-metabolizing enzymes (DMEs) (e.g., CYP3A4) and transporters (e.g., P-glycoprotein) is widely recognized. ${ }^{29,30}$ Therefore, recommended practice indicates that tissue weight, isolated sections, and description of anatomic characteristics should be documented at all times. The anatomic region and tissue characteristics (such as fatty, scarred, fibrous, etc.) should inform decisions related to the choice of tissue fraction, sample preparation, and scaling method. ${ }^{12}$

\section{Tissue/cell preparation}

Tissue/cell homogenization is universally used as the first step in sample preparation; however, standardization of methods and guidelines on protocols are still lacking. Furthermore, different tissues may require different homogenization techniques. Therefore, the type of sample (e.g., FFPE or fresh) and the available amount (e.g., biopsy or surgical samples) dictate the type of processing, buffers, and homogenization procedures. Complete and consistent homogenization and maximum recovery of proteins are crucially required. Some types of samples (e.g., fatty and fibrous tissue) are particularly challenging to homogenize. The recommendation is that efforts should be made to optimize buffers and settings of the homogenizer, incorporate sonication steps, and optimize the volume of the homogenate in order to ensure consistent and complete tissue lysis. Homogenization can be labor intensive and, therefore, automation 


\section{Table 1 Recommended criteria for the selection of proteotypic peptides in quantitative proteomics}

\begin{tabular}{|c|c|}
\hline $\mathrm{lec}$ & Rationale and comments \\
\hline \multirow{2}{*}{$\begin{array}{l}\text { Proteotypic } \\
\text { sequence }\end{array}$} & Unique peptide sequence to the target protein \\
\hline & $\begin{array}{l}\text { Unique mass }(\mathrm{m} / \mathrm{z}) \text { and fragmentation pattern } \\
\text { (selective product ions) }\end{array}$ \\
\hline \multirow{3}{*}{$\begin{array}{l}\text { Cleavable by } \\
\text { widely used } \\
\text { proteases }\end{array}$} & $\begin{array}{l}\text { The peptide should not be mapped to a } \\
\text { transmembrane domain }\end{array}$ \\
\hline & $\begin{array}{c}\text { The sequence should be cleavable by proteases } \\
\text { used for quantitative proteomics, such as trypsin } \\
\text { and/or LysC }\end{array}$ \\
\hline & $\begin{array}{l}\text { Absence of closely occurring cleavage sites in the } \\
\text { sequence (R/K in the case of trypsin); also when } \\
\text { trypsin/LysC are used, acidic environments (E, D) } \\
\text { adjacent to cleavage sites are not favorable }\end{array}$ \\
\hline \multirow{3}{*}{$\begin{array}{l}\text { Detectable by } \\
\text { LC-MS/MS }\end{array}$} & Favorable hydrophobicity (LC) and ionizability (MS) \\
\hline & $\begin{array}{l}\text { Optimal length; the ideal length depends on the } \\
\text { LC-MS platform but generally sequences with } \\
6-20 \text { amino acids are preferred }\end{array}$ \\
\hline & $\begin{array}{c}\text { Absence of SNPs and PTMs except when these } \\
\text { are targeted by the investigation }\end{array}$ \\
\hline \multirow[t]{2}{*}{ Stability } & $\begin{array}{l}\text { Stable to spontaneous chemical modifications } \\
\text { during handling and storage, such as deamidation } \\
\qquad(\mathrm{N}, \mathrm{Q}) \text { and oxidation }(\mathrm{M})\end{array}$ \\
\hline & $\begin{array}{l}\text { Complete and/or consistent alkylation should be } \\
\text { ensured for peptides with cysteine }(\mathrm{C}) \text { residues }\end{array}$ \\
\hline \multicolumn{2}{|c|}{$\begin{array}{l}\text { Criteria can be used in targeted quantitative techniques (MRM, PRM) and } \\
\text { certain global analyses (e.g., DDA-HiN, SWATH) for the selection of surrogate } \\
\text { peptides to represent the proteins of interest. } \\
\text { C, cysteine; D, aspartic acid; E, glutamic acid; HiN, high N peaks approach; } \\
\text { K, Iysine; LC, liquid chromatography; LC-MS/MS, liquid chromatography- } \\
\text { tandem mass spectrometry; LysC, lysyl endopeptidase; M, methionine; MRM, } \\
\text { multiple reaction monitoring; MS, mass spectrometry; m/z, mass-to-charge } \\
\text { ratio; N, asparagine; PRM, parallel reaction monitoring; PTMs, posttranslation } \\
\text { modifications; Q, glutamine; R, arginine; SNPs, single-nucleotide } \\
\text { polymorphisms; SWATH, sequential window acquisition of all theoretical } \\
\text { fragment mass spectra. }\end{array}$} \\
\hline
\end{tabular}

can be applied with larger sample batches (e.g., archived biofluids or tissues from longitudinal studies). In addition to homogenization, a brief sonication step can be used to break up any cells that remain in suspension. After complete tissue lysis is confirmed, normally visually or by measuring the amount of protein in homogenate (e.g., using a colorimetric assay), homogenates can either be prepared directly by subsequent protein digestion ${ }^{30-32}$ or further processed by enriching certain fractions (e.g., crude membrane/microsomes, plasma membrane, and cytosol). ${ }^{19,33,34}$ Total protein quantification prior to digestion can be highly variable depending on the type of assay used (e.g., bicinchoninic acid, Bradford, Lowry, and tryptophan-based fluorescence analysis). When comparing data from different laboratories, variability in total protein determination should be considered.

Whole-cell lysates and enriched fractions. Currently, the majority of laboratories working on ADME proteomics use membrane fractions, although there is growing interest in whole-cell lysates. ${ }^{17}$ Theoretically, using cell lysates should constitute the best option for quantitative protein analysis because of reduced losses of analyte; however, signal from lysates tend to be lower with current analytical capability, and enrichment is, therefore, often used to improve the quality of analysis. This allows quantification of low abundance proteins by improving signal-to-noise ratios and reducing matrix complexity (Table $\mathbf{2 A}$ ). However, enrichment usually leads to unpredictable protein loss that may require estimation in the form of loss/recovery factors. ${ }^{35}$ Scaling factors describing membrane protein per gram tissue (e.g., microsomal protein per gram liver/kidney (MPPGL/MPPGK)) are important for IVIVE, and these are estimated based on total protein yield relative to tissue mass, with large technical variability observed in these scalars. The workshop participants reported that typically $\sim 50 \%$ of the crude membrane preparation is lost into other fractions, ${ }^{36}$ necessitating corrections based on assessment of enrichment markers. There is currently considerable debate about suitable markers and enrichment is likely dependent on protein localization. For example, $\mathrm{Na}^{+} / \mathrm{K}^{+}$ATPase and calnexin have previously been used as markers for basolateral plasma membrane and reticular microsomal membrane, respectively. ${ }^{22,31,37}$
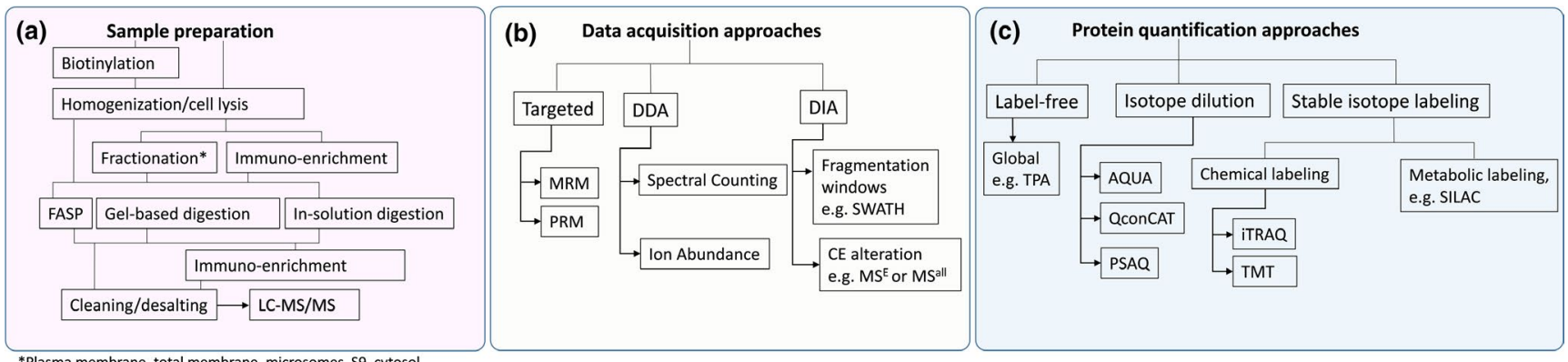

Figure 2 Overview of methods used for sample preparation and protein measurement using LC-MS/MS proteomics. (a) Various sample preparation and digestion techniques. Biotinylation is only applicable to cell lines. Immuno-enrichment can either be used at the protein or peptide level. Plasma membrane/total membrane/S9/microsomes/cytosol are fractions generated either using centrifugation or membrane extraction kits. (b) Various protein quantification assays. (c) LC-MS/MS data acquisition approaches. AQUA, absolute quantification peptides; DDA, data-dependent acquisition; DIA, data-independent acquisition; FASP, filter-aided sample preparation; iTRAQ, isobaric tags for relative and absolute quantification; LC-MS/MS, liquid chromatography tandem mass spectrometry; MRM, multiple reaction monitoring; PRM, parallel reaction monitoring; PSAQ, protein standards for absolute quantification; QconCAT, quantitative concatemer; SILAC, stable-isotope labeling by amino acids in cell culture; SWATH, sequential window acquisition of all theoretical fragment ion spectra; TMT, tandem mass tags; TPA, total protein approach. 
Table 2 Pros, cons, and recommended applications of various sample preparation, protein digestion, and LC-MS/MS proteomics methods used in translational pharmacology research

Recommended applications in translational pharmacology research Technique Pros (P1-P52) Cons and assumptions (C1-C48) (A1-A27)

A. Sample preparation

Whole-cell P1. Limited processing/handling lysate

P2. Time-efficiency, cost-effectiveness, and minimal labor

P3. Can be used to capture a proteomic fingerprint of the sample with high resolution and high sensitivity MS platforms (by global proteomics)

P4. The whole proteome can be analyzed and all protein is accounted for (by global proteomics)

Enriched frac- $\quad$ P5. Improved precision of membrane protein tions (total membrane, HLM, plasma membrane, cytosol) estimates, especially those expressed at lower abundance (using targeted or global proteomics)

P6. The matrix is less complex than whole cell lysates

P7. Analysis can be done on standard to high-end MS platforms

P8. Proteins localized to certain subcellular compartments requires subcellular enrichment
C1. Highly complex matrix and low abundance of proteins make analysis of certain targets challenging

C2. Requires high-end MS platforms

A1. Proteome-wide analysis

A2. Elucidation of pathways and protein networks

A3. Acquisition of data for analysis using systems biology

C3. Labor and time-intensive compared to whole lysates

C4. Loss of protein is inevitable and recovery factors are needed, which are not always consistent

C5. A fraction of the proteome is analyzed because enrichment gives information on only the enriched fraction

C6. Variable purity of enriched fraction and inconsistency of recovery make scaling back to tissue complicated

C7. Larger amount of tissue and number of cells is required compared to preparation of whole cell lysate

C3-C7

Density-gradient centrifugation

P6, P7

P9. Enrichment of membrane fractions allow improved detection of transporters and receptors

Total membrane extraction kits

P6, P7

P10. Enrichment of membrane fractions allow improved assessment of enzymes, transporters, and receptors

$P 11$. Less labor-intensive than biotinylation and density gradient methods

P12. Works for low tissue amounts (10-100 mg)

Biotinylation P6, P7, P9

of membrane

proteins

\section{C3-C7}

C3-C6
A4. Analysis of low abundance targets A5. Generation of fractions used in metabolism studies (e.g., HLM)
A6. Quantification of plasma membrane proteins (e.g., transporters)
C3

C8. Marker proteins should be analyzed in all fractions to generate recovery factors for IVIVE

C9. Biotinylation reagents can affect total protein quantification and digestion

C10. Biotinylation may affect membrane permeability, resulting in labeling of cytosolic proteins
B. Solubilization and digestion techniques

FASP (and P13. Versatile sample preparation method MED-FASP) applicable to different systems
P14. Sample digestion and cleaning are done on the filter

P15. Compatible with a variety of buffers and widely used solubilizing agents (SDS, deoxycholate)

P16. Different filter cutoff molecular weights available $(10,30,50$, and $100 \mathrm{kDa})$
C11. Not compatible with low amounts of sample protein

C12. Not compatible with high amounts of SDS and certain detergents (e.g., Triton and Tween)

C13. Not compatible with fractions extracted using membrane extraction kits
A8. Determination of plasma membrane-resident transporter proteins
A7. Quantification of membranebound proteins

(e.g., enzymes and transporters)
A9. Quantification of ADME proteins in whole lysate or enriched fractions

(Continues) 
Table 2 (Continued)

\begin{tabular}{|c|c|c|c|}
\hline Technique & Pros (P1-P52) & Cons and assumptions (C1-C48) & $\begin{array}{l}\text { Recommended } \\
\text { applications in } \\
\text { translational phar- } \\
\text { macology research } \\
\text { (A1-A27) }\end{array}$ \\
\hline $\begin{array}{l}\text { Gel-based sam- } \\
\text { ple preparation/ } \\
\text { GASP }\end{array}$ & $\begin{array}{l}\text { P17. Sample digestion and cleaning are } \\
\text { done in the gel } \\
\text { P18. Gels can resolve truncated proteins } \\
\text { P19. Compatible with membrane fractions } \\
\text { extracted using kits } \\
\text { P20. Compatible with low amounts of } \\
\text { protein } \\
\text { P21. Compatible with both LC-MS and blot- } \\
\text { ting techniques }\end{array}$ & $\begin{array}{l}\text { C14. Not compatible with certain detergents (e.g. } \\
\text { Triton and Tween) and chaotropes (urea) } \\
\text { C15. GASP is more cumbersome than FASP } \\
\text { C16. GASP reagents lead to propionamide modi- } \\
\text { fication of lysine residues, leading to missed } \\
\text { cleavages } \\
\text { C17. Requires extra equipment } \\
\text { C18. Protein loss can occur in gels leading to } \\
\text { requirement for recovery estimation }\end{array}$ & $\begin{array}{l}\text { A10. Quantification } \\
\text { in low amounts of } \\
\text { complex samples } \\
\text { that require thor- } \\
\text { ough cleaning }\end{array}$ \\
\hline $\begin{array}{l}\text { In-solution sam- } \\
\text { ple preparation }\end{array}$ & P19 and P20 & $\begin{array}{l}\text { C19. Cleaning of sample is required normally using } \\
\text { solvent based protein extraction } \\
\text { C20. Solution sample preparation is more cumber- } \\
\text { some than FASP } \\
\text { C21. Removal of choatropes and detergents is } \\
\text { challenging }\end{array}$ & $\begin{array}{c}\text { A11. Quantification } \\
\text { of fractions ex- } \\
\text { tracted with kits }\end{array}$ \\
\hline $\begin{array}{l}\text { New techniques: } \\
\text { iST (integreated } \\
\text { stage tips); } \\
\text { SP3 (bead } \\
\text { based sample } \\
\text { preparation) }\end{array}$ & $\begin{array}{c}\text { P20 } \\
\text { P22. Proteins are cleaned and digested } \\
\text { directly in the kit } \\
\text { P23. Comparable results to FASP }\end{array}$ & $\begin{array}{l}\text { C22. These methods are not widely used, requiring } \\
\text { further validation }\end{array}$ & $\begin{array}{l}\text { A12. Quantification } \\
\text { of ADME proteins } \\
\text { in low amounts of } \\
\text { protein samples }\end{array}$ \\
\hline \multicolumn{4}{|c|}{ C. LC-MS/MS proteomics approaches } \\
\hline $\begin{array}{l}\text { Global } \\
\text { (DDA)-TPA }\end{array}$ & $\begin{array}{l}\text { P24. High coverage (whole proteome-wide } \\
\text { quantitative analysis), e.g., thousands of } \\
\text { proteins can be quantified } \\
\text { P25. Prior knowledge of proteotypic pep- } \\
\text { tides and MS parameters is not required. } \\
\text { Universally available LC and MS methods } \\
\text { are used } \\
\text { P26. Unbiased analysis of all peptides and } \\
\text { MS fragments allows global label-free } \\
\text { quantification of all protein using a single } \\
\text { or few protein standards or using TPA } \\
\text { P27. Peptide internal standards are not } \\
\text { needed } \\
\text { P28. MS and MS/MS data generated using } \\
\text { the untargeted approach can be used to } \\
\text { develop targeted methods. This is particu- } \\
\text { larly applicable when developing methods } \\
\text { for proteins not available in the literature } \\
\text { P29. Hypothesis-generating data are } \\
\text { obtained, which can be archived in } \\
\text { databases } \\
\text { is used with LC-MS }\end{array}$ & $\begin{array}{l}\text { C23. Longer LC run time and requirement of nano- } \\
\text { LC system } \\
\text { C24. Requirement of high resolution mass spec- } \\
\text { trometry (HR-MS) instruments (e.g., Orbitrap, } \\
\text { TOF) for data acquisition } \\
\text { C25. Not efficient if the purpose is to quantify a } \\
\text { limited number of proteins } \\
\text { C26. Cannot yet be used for assessment of poly- } \\
\text { morphic variants } \\
\text { C27. Highly homologous proteins may overlap } \\
\text { C28. The TPA method needs to be validated across } \\
\text { laboratories to be established as a routine abso- } \\
\text { lute quantification method } \\
\text { C29. Requires bioinformatics expertise not typically } \\
\text { available in ADME/PD laboratories }\end{array}$ & $\begin{array}{l}\text { A13. Proteome-wide } \\
\text { quantitative finger- } \\
\text { print of a sample } \\
\text { A14. Method devel- } \\
\text { opment for new } \\
\text { proteins } \\
\text { A15. Systems } \\
\text { biology and QSP } \\
\text { applications } \\
\text { A16. Unbiased } \\
\text { characterization of } \\
\text { PTMs } \\
\text { A17. Identification } \\
\text { of protein-protein } \\
\text { networks }\end{array}$ \\
\hline
\end{tabular}




\section{Table 2 (Continued)}

\begin{tabular}{|c|c|c|c|}
\hline Technique & Pros (P1-P52) & Cons and assumptions (C1-C48) & $\begin{array}{l}\text { Recommended } \\
\text { applications in } \\
\text { translational phar- } \\
\text { macology research } \\
\quad(\mathrm{A} 1-\mathrm{A} 27)\end{array}$ \\
\hline AQUA/MRM & $\begin{array}{l}\text { P32. High sensitivity } \\
\text { P33. High precision and reproducibility } \\
\text { P34. Stable labeled internal standards ad- } \\
\text { dress matrix effect } \\
\text { P35. Because most of the DMPK laborato- } \\
\text { ries have expertise on quantitative MRM } \\
\text { analysis of small molecules, facile train- } \\
\text { ing is possible } \\
\text { P36. Conventional triple quadrupole instru- } \\
\text { ments are used. HR-MS instrument are } \\
\text { not required } \\
\text { P37. MS/MS parameters can be optimized } \\
\text { using proteotypic peptide standards. }\end{array}$ & $\begin{array}{l}\text { C30. Limited resolution and compromised selectiv- } \\
\text { ity due to interfering peaks } \\
\text { C31. Limited coverage (10-40 proteins/run) } \\
\text { C32. Prior knowledge of proteotypic peptides and } \\
\text { MS parameters is required } \\
\text { C33. Quantification is based on limited number of } \\
\text { peptides (1-3), which can be compromised if the } \\
\text { selected proteins are prone to modification by } \\
\text { PTM/SNP } \\
\text { C34. Custom synthesis of proteotypic peptide } \\
\text { standards is expensive and can take } 3-4 \text { weeks } \\
\text { C35. Does not account for the protease digestion } \\
\text { efficiency associated with tissue samples }\end{array}$ & $\begin{array}{l}\text { A18. Targeted analy- } \\
\text { sis of a limited } \\
\text { number of low to } \\
\text { high abundance } \\
\text { DMEs, transport- } \\
\text { ers, and receptors }\end{array}$ \\
\hline QconCAT (MRM) & $\begin{array}{c}\text { P32-P34, P36 } \\
\text { P38. Labeled concatemers address matrix } \\
\text { effects, sample loss during preparation } \\
\text { and inconsistency in protease digestion } \\
\text { P39. Unique advantage in allele-specific } \\
\text { protein quantification and assessment of } \\
\text { inter-correlations } \\
\text { P40. Transferability of the plasmid between } \\
\text { laboratories and sustainability of stand- } \\
\text { ard protein if protein expression expertise } \\
\text { is available }\end{array}$ & $\begin{array}{c}\text { C30-C33 } \\
\text { C36. Developing QconCAT peptides takes substan- } \\
\text { tial efforts, therefore, making it hard to switch } \\
\text { peptides used to monitor protein expression } \\
\text { C37. Does not necessarily account for the protease } \\
\text { digestion efficiency associated with tissue } \\
\text { samples } \\
\text { C38. Potential contamination of light peptides in } \\
\text { the heavy standard because complete labeling } \\
\text { cannot be achieved. The subtraction of light pep- } \\
\text { tide signal from heavy peptide signal can yield } \\
\text { erroneous results in the case of low abundant } \\
\text { proteins }\end{array}$ & $\begin{array}{l}\text { A19. Assessment } \\
\text { of protein-protein } \\
\text { inter-correlations } \\
\text { A20. Allele- } \\
\text { specific protein } \\
\text { quantification }\end{array}$ \\
\hline PRM (MRM-HR) & $\begin{array}{c}\text { P32-P34 } \\
\text { P41. High selectivity } \\
\text { P42. Unbiased targeted analysis of all } \\
\text { theoretical fragments. A pre-selected list } \\
\text { of peptide transitions to be monitored is } \\
\text { not required }\end{array}$ & $\begin{array}{l}\text { C24, C31, C32 } \\
\text { C39. Compromised/moderate signal of low abun- } \\
\text { dant proteins }\end{array}$ & $\begin{array}{l}\text { A21. Targeted analy- } \\
\text { sis of moderately } \\
\text { to highly abundant } \\
\text { proteins } \\
\text { A22. Absolute and } \\
\text { relative quantifi- } \\
\text { cation of target } \\
\text { proteins }\end{array}$ \\
\hline SWATH & $\begin{array}{c}\text { P24, P26-P30 } \\
\text { P43. Allows both quantitative and discovery } \\
\text { proteomics } \\
\text { P44. Gas-phase fractionation possible } \\
\text { P45. Greater sensitivity and coverage than } \\
\text { DDA and LC-MS }\end{array}$ & $\begin{array}{c}\text { C23-C27, C29 } \\
\text { C40. Low to moderate sensitivity }\end{array}$ & $\begin{array}{l}\text { A13-A17 and } \\
\text { A21-A22 }\end{array}$ \\
\hline TMT/ITRAQ & $\begin{array}{l}\text { P46. Multiple samples can be analyzed in a } \\
\text { single LC-MS run } \\
\text { P47. Increased sensitivity due to chemical } \\
\text { devitalization }\end{array}$ & $\begin{array}{l}\text { C41. Expensive reagents and cumbersome } \\
\text { methodology }\end{array}$ & $\begin{array}{l}\mathrm{A} 15-\mathrm{A} 19 \text { and } \\
\mathrm{A} 21-\mathrm{A} 22\end{array}$ \\
\hline SILAC/SILAM & P48. High precision & $\begin{array}{l}\text { C38 } \\
\begin{array}{l}\text { C42. Limited to cell culture or expensive SILAC } \\
\text { rodent models }\end{array} \\
\text { C43. Not practical technique for human tissue }\end{array}$ & $\begin{array}{c}\text { A13-A17 (limited to } \\
\text { cell culture/SILAC } \\
\text { in animals) } \\
\text { A23. Cell culture } \\
\text { experiments, } \\
\text { such as enzyme } \\
\text { induction and } \\
\text { suppression } \\
\text { A24. Rate of protein } \\
\text { synthesis }\end{array}$ \\
\hline PSAQ & P49. Reliable absolute protein quantification & $\begin{array}{c}\text { C38 (if labeled protein is used as calibrator) } \\
\text { C44. Very limited coverage because of non-availa- } \\
\text { bility of protein standards }\end{array}$ & $\begin{array}{l}\text { A25. Reliable } \\
\text { absolute protein } \\
\text { quantification }\end{array}$ \\
\hline
\end{tabular}

(Continues) 
Table 2 (Continued)

\begin{tabular}{|c|c|c|c|}
\hline Technique & Pros (P1-P52) & Cons and assumptions (C1-C48) & $\begin{array}{l}\text { Recommended } \\
\text { applications in } \\
\text { translational phar- } \\
\text { macology research } \\
\text { (A1-A27) }\end{array}$ \\
\hline LC-MSE & $\begin{array}{c}\text { P24-P31, P44 } \\
\text { P50. Greater sensitivity and coverage than } \\
\text { global DDA }\end{array}$ & $\begin{array}{c}\text { C23-C27, C29 } \\
\text { C45. Lower coverage than SWATH }\end{array}$ & A13-A17, A21-A22 \\
\hline $\begin{array}{l}\text { Spectral } \\
\text { counting }\end{array}$ & $\begin{array}{c}\text { P51. Convectional method. Multiple } \\
\text { software packages and expertise are } \\
\text { available }\end{array}$ & $\begin{array}{c}\text { C23-C27 } \\
\text { C46. Requirement of software packages (e.g., } \\
\text { APEX, Crux, emPAI calc, PepC, QSpec, QProt, } \\
\text { and Spectral Index) } \\
\text { C47. Not state-of-the-art due to low precision/ } \\
\text { accuracy }\end{array}$ & $\begin{array}{c}\text { A26. Stoichiometric } \\
\text { assessment }\end{array}$ \\
\hline Ion intensity & P52. Better precision than spectral counting & $\begin{array}{c}\text { C23-C27 } \\
\text { C48. Requirement of software for peak pick- } \\
\text { ing and extracted chromatogram alignment } \\
\text { (e.g., MapQuant, MaxQuant, OpenMS, Peaks } \\
\text { Studio, Progenesis QI (Nonlinear Dynamics), } \\
\text { ProSE (Proteios Software Environment), Serac, } \\
\text { SpecArray, and SuperHirn) }\end{array}$ & $\begin{array}{l}\text { A27. Global profil- } \\
\text { ing of biological } \\
\text { samples }\end{array}$ \\
\hline
\end{tabular}

ADME, absorption, distribution, metabolism, and excretion; AQUA, absolute quantification standards; DDA, data-dependent acquisition; DME, drug-metabolizing enzyme; DMPK, drug metabolism and pharmacokinetics; FASP, Filter-aided sample preparation; GASP, gel-aided sample preparation; HLM, human liver microsomes; HR-MS, high resolution mass spectrometry; IM, ion mobility; iST, integrated stage tips; iTRAQ, isobaric tags for relative and absolute quantitation; IVIVE, in vitro-in vivo extrapolation; LC-MSE, liquid chromatography-mass spectrometry by collision energy alteration; LC-MS/MS, liquid chromatography-tandem mass spectrometry; MRM, multiple reaction monitoring; MRM-HR, high resolution multiple reaction monitoring; MS, mass spectrometry; PD, pharmacodynamics; PSAQ, protein standards

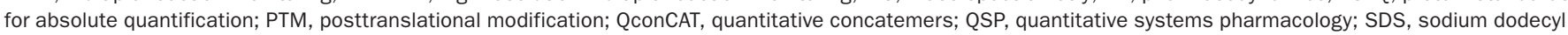
sulfate; SILAC, stable isotope labeling in cell culture; SNP, single nucleotide polymorphism; SP3, single pot solid phase-enhanced sample preparation; SWATH, sequential window acquisition of all theoretical fragment mass spectra; TMT, tandem mass tags; TOF, time-of-flight; TPA, total protein approach.

Membrane enrichment is carried out using various centrifugation or membrane extraction methods, often as commercial kits. A substantial amount of published transporter data are generated using these kits; however, no systematic assessment of the quality of kit-enriched fractions has been reported. Although most reported analyses have been done on enriched fractions, ${ }^{36,37}$ consensus suggests that quantification in tissue homogenates will be widely used in the future, driven by rapid advances in LC-MS technology and the availability of new methods that provide higher yields of cellular proteins. When homogenates are analyzed with global proteomics, a larger number of proteins can be identified than is practically possible in enriched membrane preparations, such as plasma membrane fractions. Unbiased and reliable quantification of a larger number of proteins provides a more realistic profile of biological processes ${ }^{38}$; however, this is currently challenging for low abundance proteins, for which fewer unique peptides are identified. ${ }^{17}$ Another proposed approach requires analysis of all fractions from different cellular compartments followed by reconstruction of protein expression profiles using bioinformatics. Corrections are made by analysis of the homogenate. ${ }^{37}$ This is expected to generate a rich set of data that should allow better characterization of the system under study. ${ }^{36}$

Analysis of plasma membrane proteins. Plasma membrane fractions generated using gradient centrifugation suffer from higher plasma protein loss than crude membrane preparations; protein recovery is lowest in purified fractions, such as plasma membrane $<$ total membrane fractions $<$ homogenate. However, transporter proteins resident in the plasma membrane are preferentially quantified in purified fractions compared with total transporter protein, which can also be distributed into intracellular membranes. Plasma membrane fractionation techniques work under the assumption that only proteins localized on the plasma membrane at the time of extraction are available to carry out the relevant activity. ${ }^{39}$

Alternative methods proposed to assess plasma membrane transporters/receptors use derivatization of cell-surface proteins before analysis using a chemical tag, such as a modified biotin moiety. ${ }^{40}$ It is reasonable to assume that quantification of plasma membrane-resident transporters (instead of normalizing to a membrane marker) should yield better scaling factors. However, the biotinylation protocol is cumbersome and requires several additional steps, which leads to the requirement for additional quality controls. In addition, to date, the biotinylation method has only been reported to be applicable to cellular systems and not to tissue samples. ${ }^{40,41}$ Provided the abundance of plasma membrane transporters is not sensitive to cross-laboratory differences in culturing techniques, surface-labeling methods can provide valuable information for proteins in the plasma membrane of cells (e.g., hepatocytes), which could be used by others for future IVIVE without having to establish this technique in their laboratory. ${ }^{41}$ However, until this assumption is verified, researchers are recommended to quantify cell-surface abundance of proteins in cells grown in their own laboratory.

Immuno-enrichment methods. To address the above-mentioned limitations of tissue lysates and enriched fractions, immunoenrichment represents a middle ground, which has recently yielded results of high precision. ${ }^{42}$ Enrichment with antibodies can 
take place at the protein level, ${ }^{43}$ with applications in elucidating transcription regulatory networks, cell signaling pathways, and biomarker discovery, or postdigestion at the peptide level for peptide enrichment before LC-MS/MS. ${ }^{42}$ An example of such technique is Stable Isotope Standards and Capture by AntiPeptide Antibodies (SISCAPA), also referred to as immunoselected reaction monitoring technology. ${ }^{43}$ This approach allows reduction of matrix complexity within a whole-cell digest by enriching only the desired peptides, followed by MS analysis. Immuno-enrichment is not inherently capable of distinguishing between intracellular and plasma membrane proteins and adding a biotinylation step to this method could theoretically combine the advantages of the two techniques. In cell lysates, the lower reproducibility observed with the lower range of protein expression can be addressed by immuno-enrichment of peptides from these targets ${ }^{17}$; however, generating antibodies for all required targets with sufficient specificity remains a complex challenge, leading to limited proteome coverage. ${ }^{42}$ Multiplexing is also challenging with these technologies and the presence of protein variants (e.g., SNPs and PTMs) can lead to changes in the dynamics of interaction between the antibodies and their target analytes.

\section{Protein extraction and digestion methods}

Proteins are extracted using detergents before proteolytic digestion. Detergents frequently used include sodium dodecyl sulfate, deoxycholate, or MS-compatible products, such as RapiGest and ProteaseMAX. Chaotropes, such as urea, are sometimes used for extraction and denaturation during digestion. Protease inhibitors used in tissue homogenization and preparation of cellular fractions can affect proteolytic enzyme activity, which can compromise in-solution digestion protocols, and, therefore, samples

(a)

(b)

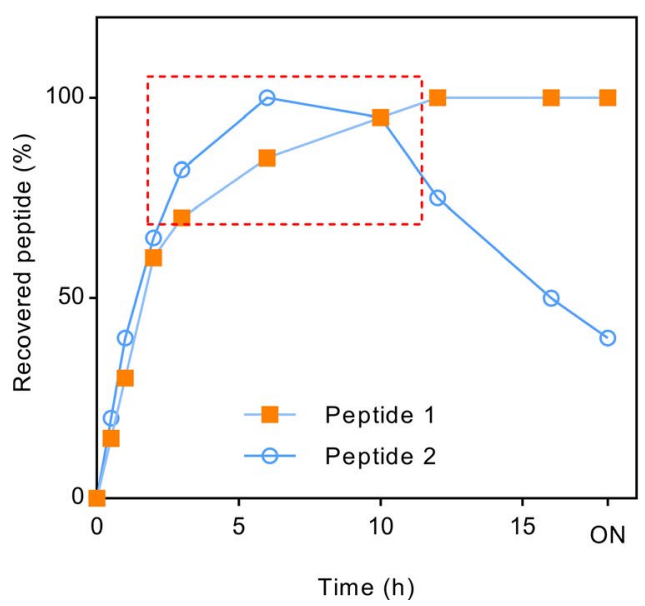

should undergo solvent extraction, cleaning, or buffer exchange before proteolysis. The choice of protease is dependent on the purpose of the experiment, and in routine analyses, the use of more than one protease is reported to increase the depth of analysis. Several views from the participants were in support of using proteases in combination for incremental gain in identified peptides (i.e., increased coverage in the region of $20 \%$ in different laboratories when two or more proteases are used). ${ }^{44}$ Other advantages of using multi-enzyme digestion in global proteomics include improved sensitivity and precision. ${ }^{45}$ However, opposing views pointed to higher reproducibility across laboratories when using only trypsin and further questioned whether the value of using other proteases with trypsin justifies the additional cost. A point to consider is that the enzyme:protein ratio should always be optimized for maximum digestion efficiency prior to the experiment, and, in the case of trypsin, the amount of enzyme used should allow minimal chymotryptic activity due to trypsin autolysis. Maximum digestion efficiency does not necessarily imply complete digestion of proteins, and, therefore, time-dependent protein-to-peptide conversion during digestion should be monitored by quantifying the amount of processed protein and content of released peptides and assessing the extent of missed cleavages (Figure 3a,b). Measuring the concentration of released peptides provides an additional QC for optimal loading onto the LC-MS/ MS system. ${ }^{46}$

Three general types of sample preparation/protein digestion approaches are widely used: in-solution, gel-based, or filter-aided methods (Table 2B). These methods are used for various reasons and certain applications are more suited to specific methods. Comparative investigations have previously assessed variants of the same method ${ }^{47}$ or similar methods ${ }^{48}$; however, no large-scale
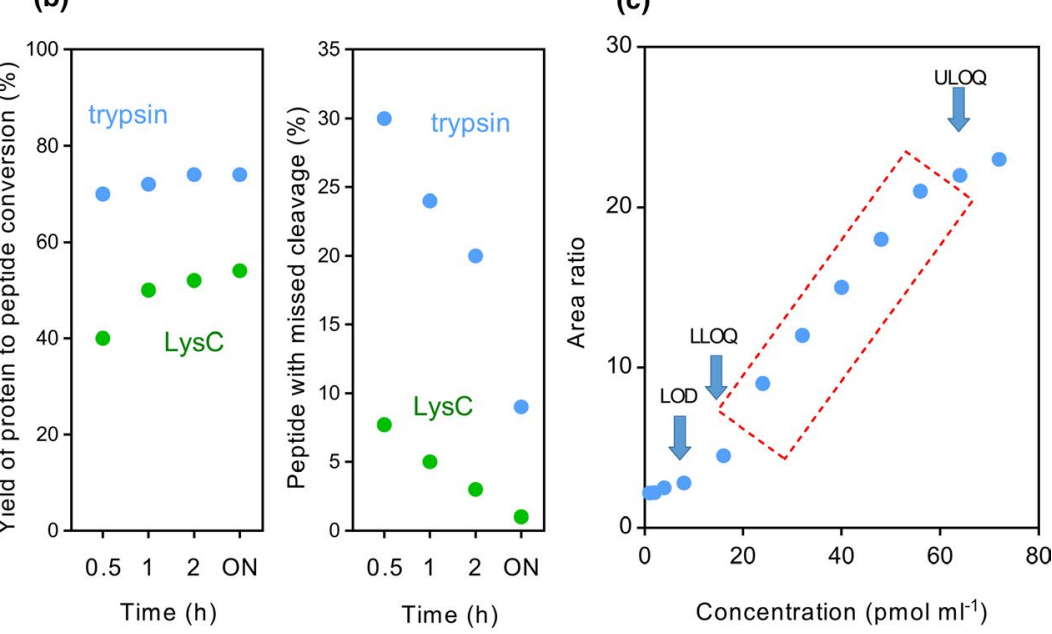

Figure 3 Practical considerations for sample digestion and quantification of proteins. (a) Time-dependent digestion profiles of two representative peptides used for targeted quantification. Typically, peptides are rapidly released during the first 0-4 hours when trypsin activity is at maximum. The trypsin digestion rate slowly reaches a plateau and sometimes peptides can degrade after reaching maximum release. The red dotted rectangle indicates the optimal time for terminating trypsin digestion to avoid regions of rapid formation or degradation when performing targeted analysis using multiple peptides. (b) In global proteomics, the yield of protein-to-peptide conversion and rate of missed cleavage can be monitored for optimal digestion before analysis. The profiles show digestion of a whole cell lysate using either trypsin or LysC. (c) Typical calibration curve showing linear signal range (dotted rectangle), LOD, LLOQ, and ULOQ. Signal below LLOQ can be detected but is not quantifiable. Rarely, signal in absorption, distribution, metabolism, and excretion liquid chromatography tandem mass spectrometry proteomics can be saturated (ULOQ). Time is measured in hours. LLOQ, lower limit of quantification; LOD, limit of detection; ON, overnight incubation; ULOQ, upper limit of quantification. 
systematic investigation or comparative head-to-head assessment of these three types of sample preparation has been reported. For samples on which all methods can be applied, participant laboratories with experience in using more than one method reported little difference in outcomes. For certain targets, complementarity is expected with some proteins tending to be better characterized by one method over the other. However, convenience and overall "fitness for purpose" seem to favor filter-aided methods, such as filter-aided sample preparation (FASP), over other approaches, especially for global proteomics. FASP is applicable to a wide, dynamic range of protein concentration and relies on filters to remove low and high molecular nonproteinaceous cell components and to digest and clean proteins. However, FASP is not applicable with very low amounts of protein and has been shown to be compatible with only certain detergents (e.g., sodium dodecyl sulfate and deoxycholate). Several emerging methods and kits, such as integrated stage tips ${ }^{49}$ and single-pot solid phase-enhanced sample preparation kits, ${ }^{50}$ provide alternative approaches. Applicability of these methods to tissue material, which is not easily extractable, such as liver or intestine, remains to be demonstrated. Modifications of gel-based preparation methods, including gel-aided sample preparation, ${ }^{48}$ which uses gel particles to trap proteins for efficient digestion and cleaning, have also been suggested for complementary analysis and for very low amounts of protein. However, gel-aided sample preparation tends to generate higher levels of missed cleavage due to modification of lysine with acrylamide, ${ }^{48}$ and, therefore, peptides used for quantification should be chosen carefully.

\section{Recommendations for best practice in sample preparation}

Although measurement of enzymes and transporters can be made in homogenates or enriched fractions, the current state of the art indicates that measurements in whole tissue lysates are sometimes not sensitive enough for proteins expressed at low concentrations. However, this is increasingly addressed by peptide fractionation prior to analysis. ${ }^{51}$ Matrix effects and loss of sensitivity are more likely in homogenates, and the sensitivity gained by enriching proteins should make the analysis of enriched fractions more precise and reproducible provided that the yield and reproducibility of subcellular fractionation is sufficiently controlled. Instruments used with whole-cell lysates are required to be of high resolution and stability of MS conditions over long runs should be ensured. New methods used to accurately describe plasma membrane-resident proteins, such as biotinylation, show promise but are of limited use to cellular systems and have not reached routine implementation. Immuno-enrichment can simplify the sample matrix and improve specificity to the targets; however, application is still limited (due to a limited number of high quality antibodies) and the advantages offered by its use should justify the additional cost. It is worth noting that data generated using different "systems" from the same type of tissue (e.g., homogenate vs. enriched fractions from liver tissue), should not be used in combination for downstream applications.

Protein quantification is based on proteotypic peptides, and, therefore, considerable efforts should be made to maximize digestion efficiency and release of peptides from proteins. The choice of sample digestion methods should be guided by the application and type of sample. The use of more than one protease can be advantageous and is encouraged when there is a particular application that requires different cleavage patterns, ${ }^{52}$ reduced miscleavage, and/or higher proteome coverage. ${ }^{45}$

\section{QUANTITATIVE PROTEOMIC METHODS}

Proteomic approaches can be classified based on data acquisition methods and whether protein quantification is performed using chemical or metabolic stable-isotope labeling or label-free methods (Figure $\mathbf{2 b}, \mathbf{c})$. The selection of an optimal approach depends on the requirements of the study with respect to proteome coverage, sensitivity, and precision. Global proteomics provides comprehensive proteome-wide quantification of a large number of proteins $(100 s-1,000 s)$ in a biological sample. However, these techniques can be less sensitive and reproducible compared with targeted proteomics for selected proteins. Targeted proteomics requires prospective selection of proteotypic peptides for the target proteins and this quantitative strategy is applicable to the quantification of a limited number of proteins (10s-100s). Acquisition of global proteome-wide coverage requires high-resolution MS platforms (e.g., Orbitrap, time-of-flight (TOF)), whereas quantification of selected lists of low abundance proteins (e.g., enzymes, transporters, and transcriptional factors) can be achieved in a targeted manner using simpler low-resolution triple-quadrupole instruments. The success of some quantitative proteomic experiments requires chemical derivatization for better MS ionization and sensitivity, ${ }^{53,54}$ whereas stable-isotope labeling can address experimental variability. ${ }^{55,56}$ Because several published reviews and tutorials have covered quantitative proteomics in detail, ${ }^{57-60}$ we focus here on a critical summary of the advantages, limitations, and utility of technique in ADME and PD applications (Table 2C).

\section{Data acquisition approaches}

Data acquisition approaches for quantitative proteomics can be targeted, data-dependent acquisition (DDA), and data-independent acquisition (DIA). High resolution (HR)-MS or low-resolution-MS (triple quadrupole) instruments can be used for targeted proteomics, whereas DDA and DIA approaches require HR-MS instruments. Multiple-reaction monitoring (MRM) is the most common targeted approach that relies on LC-MS/MS analysis of preselected proteotypic peptides. In MRM acquisition, precursor ions of target proteotypic peptides and a subset of their corresponding product ions are measured. Mass filtering of precursor and product ions is generally achieved in space using triple-quadrupole instruments (Figure 1a). Only a limited number of proteins (10-100) can be simultaneously quantified using MRM. In contrast, in targeted full scan MS/MS approaches, such as parallel-reaction monitoring (PRM) or MRM-HR, all product ions are measured for the corresponding precursor ions across a large number of peptides. In general, MRM is more sensitive because of the use of triple quadrupole MS; however, PRM can be more precise and selective due to HR-MS analysis. The MS/MS fragmentation in PRM can be achieved using Orbitrap or Q-TOF instruments. PRM allows postacquisition transition refinement, which is very helpful when interfering peaks coelute with target analyte fragments. Currently, the majority of drug metabolism and 
pharmacokinetics (DMPK) laboratories use MRM proteomics because of the hypothesis-driven research focus, limited number of target proteins, sufficient sensitivity of triple quadrupoles, and pre-existing expertise on the LC-MS/MS technique. ${ }^{61}$

Unlike targeted approaches, DDA is a conventional untargeted (shotgun) method, which is capable of identifying and quantifying thousands of proteins in a sample simultaneously. With DDA, several peptides can be used for quantification of each protein. Therefore, the quantification is not biased by the characteristics of one single peptide, and problems, such as coelution with other peptides, poor ionization, and poor coverage of the protein sequence, are addressed. For DDA, both MS (survey scan) and MS/MS can be utilized for the quantification of proteins. The survey scan is performed, and a fixed number of high-abundance precursor ions are selected using predetermined criteria (mostly based on intensity) and subjected to MS/MS analysis for identification. Alternatively, the MS/MS can be used for quantification, e.g., when using tandem-mass tags (TMT) or isobaric tags for relative and absolute quantitation (iTRAQ). When the TopN criteria are applied, peptides of low intensity may not be selected. ${ }^{60}$ However, often this limitation does not affect the quantification of the protein because other peptides can be selected. It is important to note that the old approach of spectral counting is considered less quantitative and, therefore, not recommended.

To address limitations of DDA, DIA is an emerging technique in global proteomics, which is capable of performing both deep untargeted (discovery) proteome coverage and targeted proteomic applications. DIA can be performed using high-speed Orbitrap and Q-TOF instruments. Unlike DDA, DIA reduces focus on highly abundant proteins by fragmentation windows (SWATH), collision energy alteration (LC-MSE), ${ }^{62}$ or the BoxCar approach. ${ }^{63}$ DIA approaches allow detection of all product ions of detectable peptide precursors present in a biological sample. These techniques combine the advantages of high-throughput shotgun proteomics and high reproducibility of MRM. In SWATH acquisition, a set of precursor acquisition windows are preselected for fragmentation, allowing acquisition of complete, high-accuracy product ion spectra of all precursors selected in each isolation window. Drawbacks of SWATH include incompatibility with conventional database searching, which would require development of vast peptide libraries specific to each setup (with correct retention times). Furthermore, coelution and cofragmentation of a mixture of precursor ions produce chimeric spectra. MS by collision energy alteration (MSE) of the full $\mathrm{m} / \mathrm{z}$ window provides high-energy and low-energy fragmentation data. The major disadvantage of MSE or MSall compared to SWATH is that the data are more complex and convoluted, which leads to the requirement for highly specialized software and high computation power. Comparative investigation showed that SWATH outperforms the MS of all precursor ions method (MSall) owing to better quality MS/MS spectra with identical MS/MS acquisition hit rates. ${ }^{64}$

\section{Label-free or label-based protein quantification approaches}

Selection of a data acquisition method alone is not sufficient for optimal quantitative results. Protein quantification usually requires the use of an external/spiked-in standard. In label-free global quantification, peptide intensities are quantified and compared across runs, which can also be compared with spiked-in unlabeled standard proteins. In principle, label-free quantification is applicable to any type of sample, including materials that cannot be metabolically labeled. High resolution and high accuracy data and optimal use of software tools are critical for the success of label-free methods. Whereas label-free quantification is widely used for measuring relative changes, it has also been implemented for determination of absolute protein abundances using the total protein approach (TPA). ${ }^{65}$ In TPA, the fractional amount of a protein in the sample is calculated by dividing the sum of signal from all peptides of the protein by the signal of all detectable peptides in the sample. ${ }^{45}$ This promising approach allows calculation of concentrations of thousands of proteins in the sample without standards. However, wide proteome coverage is a prerequisite for successful application of TPA. Using MS data from analysis of whole-cell lysates in combination with the "histone ruler,"66 protein copy numbers per cell can be estimated. Theoretically, this approach may be less prone to errors as compared with targeted analyses because it does not rely on using standards and biochemical determination of total protein in the sample. However, correlation between the peptide amount and resulting MS signal is assumed to be consistent for all peptides. Therefore, experimental validation of this approach for absolute quantification by multiple laboratories is required. Recently, a TPA strategy that uses multienzyme digestion was proposed as an alternative to targeted methods for quantification of DMEs and transporters. ${ }^{45}$

Although label-free methods are attractive, they are not widely used in translational pharmacology because of limited accessibility and low sample throughput. Essentially, LC-MS is not inherently quantitative as peptide response depends on its characteristic ionization efficiency and detection, which can be influenced by the sample matrix. This results in variable response across peptides in a sample and across a batch of samples. This limitation can be addressed by spiking synthetic stableisotope labeled (SIL) peptides, labeled protein $(s)$, or incorporating a stable-isotope label into the analyte peptides. Isotope dilution methods, such as absolute quantification (AQUA) peptides, quantitative concatemers ( $\mathrm{QconCAT}$ ) and protein standards for absolute quantification (PSAQ), do not rely on chemical or metabolic labeling of the target peptides but use external spiked-in SIL peptides or proteins. In AQUA, a known quantity of a purified SIL peptide standard is added to the sample, allowing quantitation of a protein of interest in a complex mixture using MRM. Alternatively, an SIL peptide can be used as an internal standard, where a light peptide standard is used as an external calibrator to generate a multiple-point calibration curve for more accurate quantitation across the dynamic range. ${ }^{16}$ In both cases, SIL peptides can address matrix effects and run-to-run instrument response variation. Although the term "absolute" is used in AQUA, it is essentially a peptide-based method and assumes that the protein is completely digested (i.e., 100\% digestion efficiency), with no losses in purification steps. However, digestion efficiency was reported to be impacted by solvent accessibility to the chosen peptide and three-dimensional structure of the protein at the time of digestion. ${ }^{67}$ Additionally, this 
approach does not account for peptide loss as spiking normally occurs just before LC-MS analysis. This drawback is perhaps one of the key reasons for the reported interlaboratory variability in protein abundance. ${ }^{17,68-70}$

QconCAT is a modification of the AQUA method that uses concatenated peptide sequences taken from target proteins into artificial proteins as spiked-in calibrators or internal standards. Multiple proteotypic peptides can be assembled in a single artificial protein, which allows multiplexed quantification and addresses intersample variability in protease digestion. However, similar to AQUA peptides, QconCAT does not account for peptide losses due to sample handling and digestion efficiency bias caused by solvent accessibility to the peptide in the intact native protein. Recently, QconCAT has been utilized for allele-specific quantification of DMEs. ${ }^{71,72}$ PSAQ is another modification of AQUA, in which purified labeled proteins are used as spiked-in calibrators. Quantification using labeled protein standards is considered ideal for accurate measurements; however, purified labeled proteins are expensive ${ }^{73}$ and not available for most DMEs, transporters, and receptors. A purified unlabeled protein can also be used as an external calibrator to address variability in digestion efficiency. ${ }^{16,67}$

Isotope labeling by metabolic or chemical methods can also be used to address variability in protease digestion and MS ionization. In stable-isotope labeling in cell culture (SILAC), control and treatment cells are cultured in light and heavy media to use the translational machinery of living cells to metabolically incorporate SIL amino acids. ${ }^{55,74}$ Incorporation of light and heavy amino acids into proteins creates proteomes that can precisely quantify the effect of treatment. The heavy and light samples are pooled before digestion and MS analysis. Although SILAC is generally used with cell culture, in vivo SILAC experiments are also feasible in rodents. This method is highly precise and can be applied in assessment of DDI potential, such as DME/transporter induction assays. ${ }^{75}$ The SILAC approach has also been adopted to generate global internal standards or super-SILAC mixes ${ }^{76}$ that can be used as spike-in standards for the analysis of sample proteins.

Another multiplexing approach is iTRAQ, which utilizes commercially available kits for multiplexing $2,3,4$, or 8 samples by covalently tagging primary amine groups of peptides. ${ }^{54}$ The iTRAQ reagents are isotopically labeled at different positions in such a manner that the total mass of the tag remains the same, but the fragments generated from the reagents report different masses. The samples are digested and incubated with the specific iTRAQ reagent before pooling. The pooled sample is analyzed, and the responses of specific reporter ions corresponding to individual samples generated on MS/MS analysis are reported. Using one reporter tag as calibrator, the remaining reporter peaks can be quantified. TMT labeling 5 is similar to iTRAQ, and is available as 2-plex, 6-plex, 10-plex, and 11-plex formats. Unlike iTRAQ, in addition to primary amines, cysteine or carbonyl reacting TMT reagents are also available.

\section{Recommended LC-MS techniques in DMPK and PD research} Factors that influence selection of proteomic approaches for DMPK and PD applications are (i) research aims (i.e., hypothesis-driven vs. hypothesis-generating), (ii) instrument accessibility, (iii) available expertise, and (iv) budget. In general, global proteomics is ideal for hypothesis-generating and discovery experiments, whereas targeted proteomics is generally suited for hypothesis-driven research. Targeted techniques cannot be used to identify novel proteins or pathways. Rather, a rigorous discovery workflow should start with a preliminary discovery phase based on a global proteomic method, such as a shotgun DDA or a DIA experiment, followed by verification of target proteins using more accurate targeted techniques, such as MRM or PRM. Targeted techniques will depend on prior knowledge collected in the initial discovery phase. Because triple-quadrupole MS is the most commonly used platform in DMPK/PD laboratories, AQUA is naturally a suitable quantification approach, particularly if the number of target proteins is limited and when the proposed experiment is hypothesis-driven. It is recommended that at least two proteotypic peptides should ideally be used in targeted quantification to avoid false negatives in case of posttranslational modification, rare nonsynonymous SNPs, or peptide instability. Peptides embedded in the membrane should be avoided. A prototypic peptide that is validated by multiple research laboratories can be considered. Protein quantification is based on proteotypic peptides and, therefore, cannot be claimed as "absolute protein quantification." Nevertheless, considerable effort should be made to explore and maximize recovery and digestion efficiency. In both MRM and PRM, the consensus is that multiple product ions (three or more) should be considered for reliable peptide quantification. Because smaller product ions are susceptible to interference, larger ions should be considered in MRM whenever detectable, but monitoring the loss of small fragments, such as $\mathrm{NH}_{3}$ or $\mathrm{H}_{2} \mathrm{O}$, is not recommended. A larger number of product ions should be monitored at the method development stage and the list can be subsequently refined. If possible, the transition should include a product ion with an $\mathrm{m} / \mathrm{z}$ value greater than that of the precursor to reduce interference. PSAQ is ideal for accurate measurements and should be encouraged whenever possible. Although it may be difficult to obtain standards for all the proteins, efforts can be made to generate authentic protein standards and share them across laboratories.

Label-free global proteomics is useful for simultaneous quantification of a broad range of proteins. In the workshop, several views expressed preference for TPA over conventional AQUA/PSAQ targeted methods as a "gold-standard" technique for absolute quantification; however, the majority was in favor of validated AQUA/ PSAQ assays for tier 1 applications (Table 3). Further validation by multiple laboratories is recommended to confirm TPA as a viable absolute quantification alternative for future clinical applications.

QconCAT has advantages when different variants of the same protein are targeted for phenotyping and when accurate description of expression intercorrelation is desired. ${ }^{71,72,77}$ However, developingQconCAT constructstakessubstantialefforts, ${ }^{78,79}$ which makes it hard to switch peptides when the selected peptide fails. Furthermore, QconCAT does not necessarily ensure comparable digestion efficiency to the analyte protein. Flanking regions have been suggested to improve the quality of digestion ${ }^{80}$; however, the usefulness of this approach has yet to be proven. The claim that QconCAT addresses protease digestion efficiency can be tested by randomizing the sequences of proteotypic peptides in the 
Table 3 Designating DMPK/PD applications using a tiered, fit-for-purpose approach

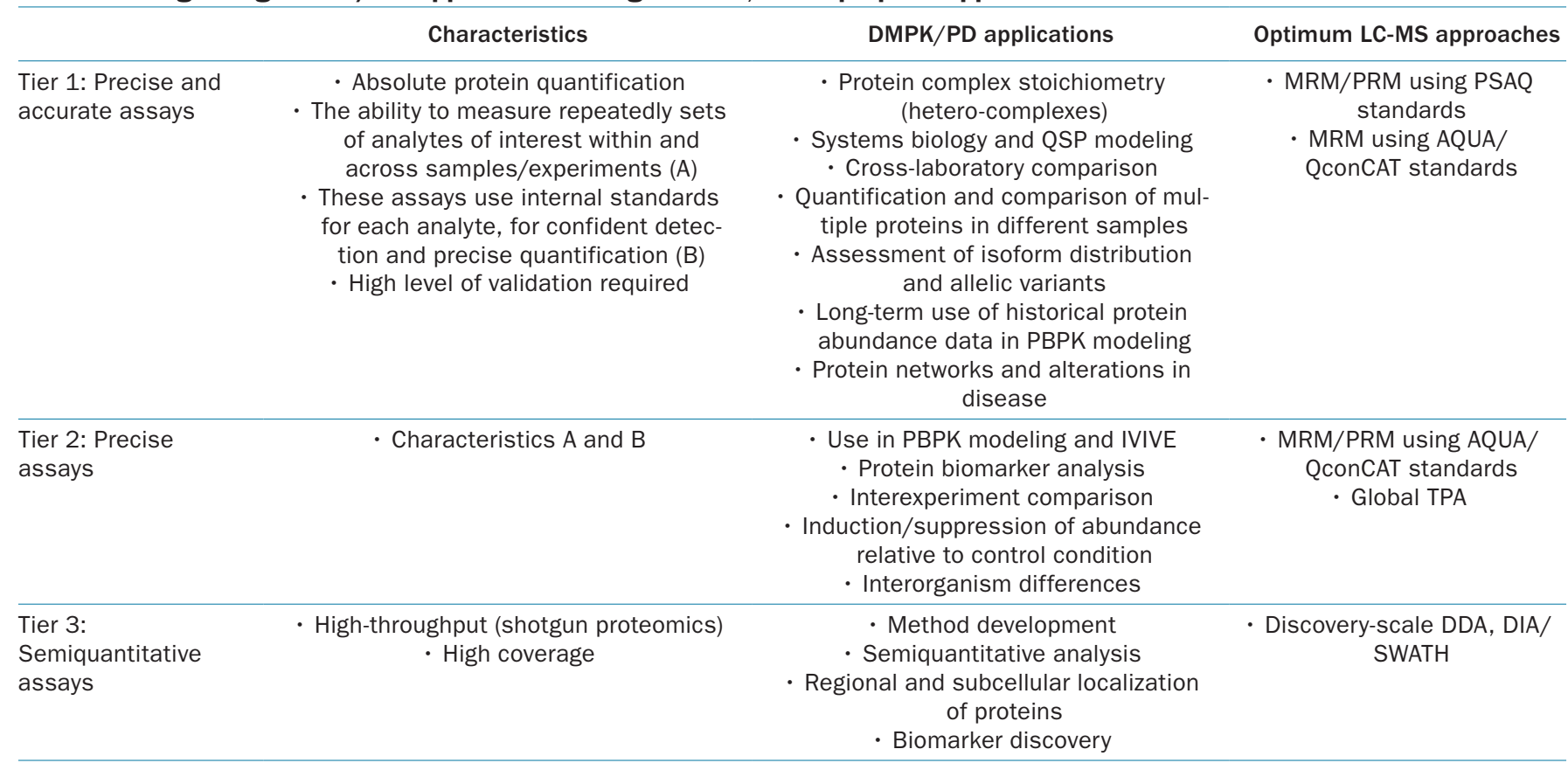

AQUA, absolute quantification; DDA, data-dependent acquisition; DIA, data-independent acquisition; DMPK, drug metabolism and pharmacokinetics; IVIVE, in vitro-in vivo extrapolation; LC-MS, liquid chromatography-mass spectrometry; MRM, multiple reaction monitoring; PBPK, physiologically-based pharmacokinetics; PD, pharmacodynamics; PRM, parallel reaction monitoring; PSAQ, protein standards for absolute quantification; QconCAT, quantitative concatemers; QSP, quantitative systems pharmacology; TPA, total protein approach.

QconCAT or including the same peptide in different QconCATs. Both SILAC and QconCAT approaches have a limitation with contamination of light peptides in the heavy standard as complete labeling cannot be achieved. Subtraction of light peptide signal from heavy peptide signal was suggested, but it can yield erroneous results in the case of low abundance proteins. ${ }^{81}$

\section{STUDY DESIGN, DATA ANALYSIS, QUALITY CONTROL, AND REPORTING}

The strategy and experimental design in a specific project will invariably depend on the aim of the study and availability of instrumentation and expertise. The study plan should be in place before the investigation commences and participants in the study, including analysts and bioinformaticians, should contribute to the study design. Considerations for data analysis should be made in the design stage with attempts to minimize changes in the selected approach after data acquisition. Methods should be validated before the experiments and should follow published method validation guidance, such as the US Food and Drug Administration $(\mathrm{FDA})^{82}$ or International Conference on Harmonization ${ }^{83}$ guidelines (e.g., tier 1 and tier 2, see Table 3).

\section{Data analysis for targeted and global proteomics}

Data acquired by targeted methods (mainly MRM and PRM) are analyzed based on initial selection of input, usually using universally available vendor-neutral software, such as Skyline ${ }^{84}$ (with its related web application Panorama ${ }^{85}$ ) or mProphet. ${ }^{86}$ In addition, default vendor software specific to different instruments can be used for assessing initial data output. Quantification is highly dependent on the choice of precursor and product ions monitored. Recommended peptide selection criteria ${ }^{18}$ are generally followed (Table 1). For MRM, the choice of the product ions should not be only based on intensity but also on the sequence. ${ }^{61}$ Criteria for targeted assay qualification (i.e., accepting data as reliable) include passing a minimum signal intensity threshold, coelution of peptide with standard, lack of interference from isobaric/isomeric peaks, and performance of the assay on quality control samples.

Compared with targeted data analysis, global data processing is more complex, which involves advanced bioinformatic tools, and the expertise of such analysis is still confined to core LC-MS facilities. Different software packages are used for this purpose depending on the type of data acquisition. Analysis of data-dependent acquisition output can either rely on signal intensity ${ }^{66,87}$ or spectral counting, ${ }^{88,89}$ with peak intensity being the more popular and arguably the more reliable approach. ${ }^{90}$ Intensity-based processing can be carried out using different software, including Progenesis QI (vendor-specific), MaxQuant, Proteios, Peaks, and OpenMS (open access). Comparative literature suggests that these software packages have similar performance and that quantitative output is sensitive to parameter settings. ${ }^{90}$ Spectral counts can be carried out using packages such as emPAI calc, PepC, QSpec, QProt, and Spectral Index. Another commonly used software, Mascot, also has an in-built emPAI calculator, which provides quantitative output with identification reports.

\section{Normalization of target protein abundance}

Data normalization is important for comparison of protein abundances across samples. Total protein amount measured using 
colorimetric assays (e.g., Lowry, Bradford, and bicinchoninic acid assays) is traditionally applied for prenormalization or postnormalization of abundance levels, leading to values expressed in units of $\mathrm{pmol} / \mathrm{mg}$ or $\mathrm{fmol} / \mu \mathrm{g}$ protein. However, this measurement is prone to errors due to incompatible buffer composition, the presence of surfactants, incomplete sample homogenization, and incorrect calibration. Consensus suggests that these methods should be improved or replaced with a more robust approach because of reported technical variability. ${ }^{91}$ A more recent alternative, which relies on tryptophan fluorescence, allows assessment of protein and peptide yield. ${ }^{46}$ Tissue mass can also be used for normalization but has the limitation of being less applicable to in vitro systems. The use of relative expression factors (absolute scaling factor/ relative expression factor ${ }^{70,92}$ ) may eliminate differences in values used for normalization, where bias from one method used in the same laboratory is expected to be consistent. ${ }^{70}$ The most promising method may be the identification of robust and universal marker proteins (e.g., housekeeping proteins), which will require rigorous validation. A distinction should be made between the use of marker proteins for normalization of abundance and those used for estimation of recovery/enrichment. The latter function can be served by several well-established protein markers, such as organelle-specific proteins with stable subcellular localization for subcellular membrane enrichment and cell-specific markers for tissue enrichment. ${ }^{37}$

\section{LLOQ and reliable protein measurements}

Most ADME proteins are of low abundance and, therefore, the LLOQ should be clearly established (Figure 3c). This parameter is normally determined using multiple measurements (normally three) of serial dilutions of the analyte in an appropriate matrix until measured amounts are too low to yield consistent quantification (e.g., coefficient of variation $>20 \%$ ). A matched matrix approach is recommended, where a blank matrix from a different species, tissue, or cell lysate can be used as diluent for the sample of interest. However, selectivity (lack of interference) should be carefully examined in the diluent matrix before use. Serial dilution of heavy internal standards in an appropriate protein matrix can also be used to confirm the LLOQ. Signal to noise ratio of $>5$ is a minimal consideration for method validation when $\geq 2$ product ions are used for quantification. Product ion quantification data should correlate and variability between them should be limited.

The LLOQ can be different for different peptides or for different product ions from a peptide. For example, it is possible that one peptide is detected in all samples but the second peptide is only detected in some samples, and, therefore, it could be misleading if peptide responses are averaged in such cases. It is recommended that protein data should be presented based on individual peptides or the peptide with higher intensity should be used as a quantifier and the other peptide can be used as a qualifier. When the qualifier is confidently identified above the limit of detection, reporting these values as below the LLOQ should be encouraged, with appropriate description, in order to caution against skewed representation of the mean toward abundant measurements. When multiple peptides from the same protein are used, individual peptide values should be assessed for correlation and fold ratios between their values. This serves to ascertain agreement between peptide measurements in terms of quantification and rank order of samples. In global proteomics, LLOQ determination is more challenging due to the heavy dependence on data analysis tools and because several peptides (with different LLOQs) are normally used together for quantification. Therefore, ideally, samples containing peptides with low signals should be repeated on multiple occasions, and the LLOQ should be determined based on the coefficient of variation between the resulting measurements.

\section{Elements related to QC}

The proteomic workflow requires assessment at each stage. Several steps were identified by participants as necessary QCs, which include:

1. Assessment of protein recovery/loss using house-keeping proteins.

2. Assessment of digestion efficiency using exogenous proteins codigested with analyte proteins, such as BSA or QconCAT constructs designed for this purpose. This can be done by monitoring missed cleavages and recovery of peptides at several intervals during digestion.

3. Assessment of protein-to-peptide conversion and miscleavage rates in global proteomics.

4. Assessment of heavy peptide stability (for targeted proteomics).

5. Assessment of subcellular markers for homogenization and enrichment performance, monitored at different stages of sample processing.

6. Assessment of day-to-day and batch-to-batch variability (reproducibility).

7. Assessment of instrument stability over long runs using internal standard response.

8. Assessment of linearity of the assay and its LLOQ.

9. Assessment of target protein yield in each fraction when fractionation is used to ensure consistency in comparing/scaling between different samples.

The required QCs should be communicated in published reports in order to support the reproducibility and, hence, the credibility and transferability of ADME proteomic data. Concerns that $\mathrm{QC}$ steps are not receiving the required level of attention are now more widely expressed and this should be emphasized in guidelines on best practice. A universal sample (e.g., tissue homogenate, microsomes, cell lysate, or customized QconCAT sample) that expresses quantifiable amounts of the target proteins can be used as a positive QC. Such positive control could be shared across laboratories to establish intralaboratory reproducibility. Efforts should be made to generate and share such universal samples (a similar approach is used in the field of therapeutic drug monitoring).

\section{Reporting of quantitative proteomic data}

There is overwhelming consensus within the proteomics community that data sharing should be more actively encouraged. This can be a requirement by journals for publications to be accepted or by granting bodies before a grant is awarded. Data can be made available to scientists, regulators, clinicians, and public 
members in a central repository, such as ProteomeXchange in the Pride database, ${ }^{93}$ and guidance should be in place to prevent unfair use of the data. Findings can be reported according to guidelines proposed by the Clinical Proteomic Tumor Analysis Consortium (CPTAC). ${ }^{61,94}$ Reporting of experimental details must be comprehensive and should include ${ }^{61}$ :

\section{Study design}

a Type and number of individual biological samples (power calculation)

b Replication (methodological, technical, and analytical)

c Type of sample preparation and LC-MS methods used

2. Assay development and optimization

a Efficiency of digestion (missed cleavage and time-dependent release of peptides)

b Stability of sample and standard peptides

c Performance of QC samples

3. Assay performance

a Specificity/selectivity

b Precision/reproducibility

c Linearity and dynamic range

d LLOQ/lower limit of detection for each analyte

4. Analytical validation and QC

5. Software and parameter settings used for file conversion and data analysis.

Manuscripts and presentations reporting quantitative proteomic data should include all experimental assumptions and a complete description of experimental conditions. Experimental vs. biological variability should be described, and, finally, the purpose of the experiment should be clearly stated with the (predefined) acceptance criteria.

\section{APPLICATIONS OF QUANTITATIVE PROTEOMICS IN TRANSLATIONAL PHARMAOCLOGY}

Key applications of quantitative proteomics in translational pharmacology (PK and PD) research are outlined in Figure 4. These highlight the relevance of such data to the discipline of clinical pharmacology as the demand for more mechanistic understanding of the handling of drugs in various patient groups and variations in drug action in patients becomes the norm, not only by regulatory agencies but also healthcare providers. There are indications suggesting that such practices should be viewed in their post-"hype" era and not just based on promise and hope of impact. ${ }^{1}$

Proteomic approaches offer an effective alternative to address the gaps associated with availability of functional probes ${ }^{92,95,96}$ by providing the link for connecting in vitro data to in vivo observations and predicting the differences between animals and humans, as well as differences between patients with various comorbidities. This covers a wide array of DMEs, transporters, and pharmacologically relevant targets, such as receptors and enzymes. This also recognizes the limitations associated with pharmacometrics and purely topdown data analyses as opposed to the more holistic QSP approach. ${ }^{97}$

Protein quantification is based on proteotypic peptides, and, therefore, to ensure consistent protease digestion, conserved proteotypic peptides should be used to assess differences between various groups (particularly interspecies differences) in the absence of purified protein standards. For cross-species differences, a "matrix approach" is recommended that relies on multiple peptides, each of which is conserved between at least two different species. The matrix approach allows estimation of the relative abundance of a certain protein across multiple species that have distinct sequences through stepwise inference of relative quantification until a matrix is built. In this case, protease digestion could also be affected by differences in the regions flanking the conserved sequences and such differences should be noted in publications. This relative approach can also be applied to comparison of tissues from different patient groups; for example, the abundance of proteins in tissues of interest can be measured relative to controls. ${ }^{9,12,13}$ It should be emphasized here that differences between populations in protein affinity for the drug $\left(\mathrm{K}_{\mathrm{m}}\right)$ or drug turnover $\left(\mathrm{k}_{\text {cat }}\right)$ cannot be addressed by proteomics, and most currently used IVIVE methods assume that differences in protein function between the control and target populations are due to abundance. However, differences in affinity and turnover caused by SNPs can be adequately identified in vitro when genotype and abundance data are available.

Scaling drug disposition from in vitro systems (e.g., microsomes, cell lines, or vesicles) to tissue(s) also makes several assumptions. First, the clearance is assumed to be directly proportional to the abundance of the "active" protein both in vitro and in vivo. Second, in the case of transporters, the proportion of transporters in the plasma membrane should either be measured in both systems or is assumed to be similar in vitro to in vivo. ${ }^{41}$ When transporter clearance is measured using overexpressed vesicles, the proportion of inside-out vesicles should be measured and a correction should be incorporated prior to IVIVE. Third, the mechanism of metabolism/transport in vitro is replicated in vivo; for example, stoichiometry of DMEs and coenzymes/cofactors (CYP reductase and cytochrome b5) in metabolic clearance predictions or membrane potential in transporter studies. ${ }^{2}$ Fourth, as indicated above, the affinity and $\mathrm{k}_{\mathrm{cat}}$ of the protein for the drug is assumed to be the same in vitro and in vivo. That is, an assumption is made that any in vivo endogenous factors (e.g., solutes and plasma proteins) that can alter the affinity or $\mathrm{k}_{\mathrm{cat}}$ of the protein are also present in the in vitro system. Recent evidence suggests that this may need to be taken into consideration for organic anion transporting polypeptides. ${ }^{98,99}$

If values from several laboratories are to be integrated for IVIVE, absolute protein quantification (i.e., tier 1) is critical. For example, absolute protein levels are essential if information on the abundance of a DME or transporter in human tissues from one laboratory is to be used in conjunction with information from another laboratory on transporter/metabolic clearance of a drug in a recombinant system. To accomplish this successfully, quantification of proteins should be standardized across laboratories. Indeed, harmonization was the goal of this workshop. However, until such standardization is achieved, an alternative approach to IVIVE is recommended using relative scaling approaches, such as absolute scaling factor/ relative expression factor. ${ }^{70,92,100}$ In this approach, if both datasets are generated in the same laboratory and relative protein extraction and digestion efficiencies for cell and tissue samples are similar, a relative expression factor can be established among systems for IVIVE 


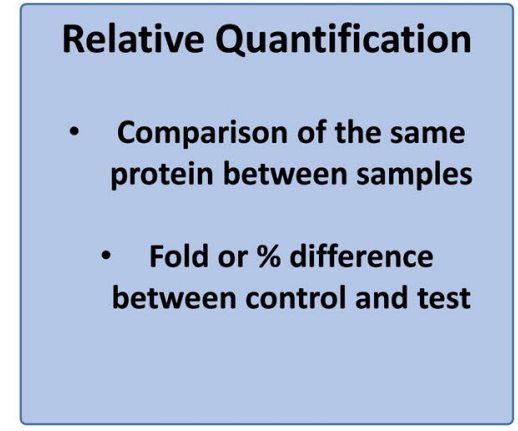

Sub-cellular localization of proteins
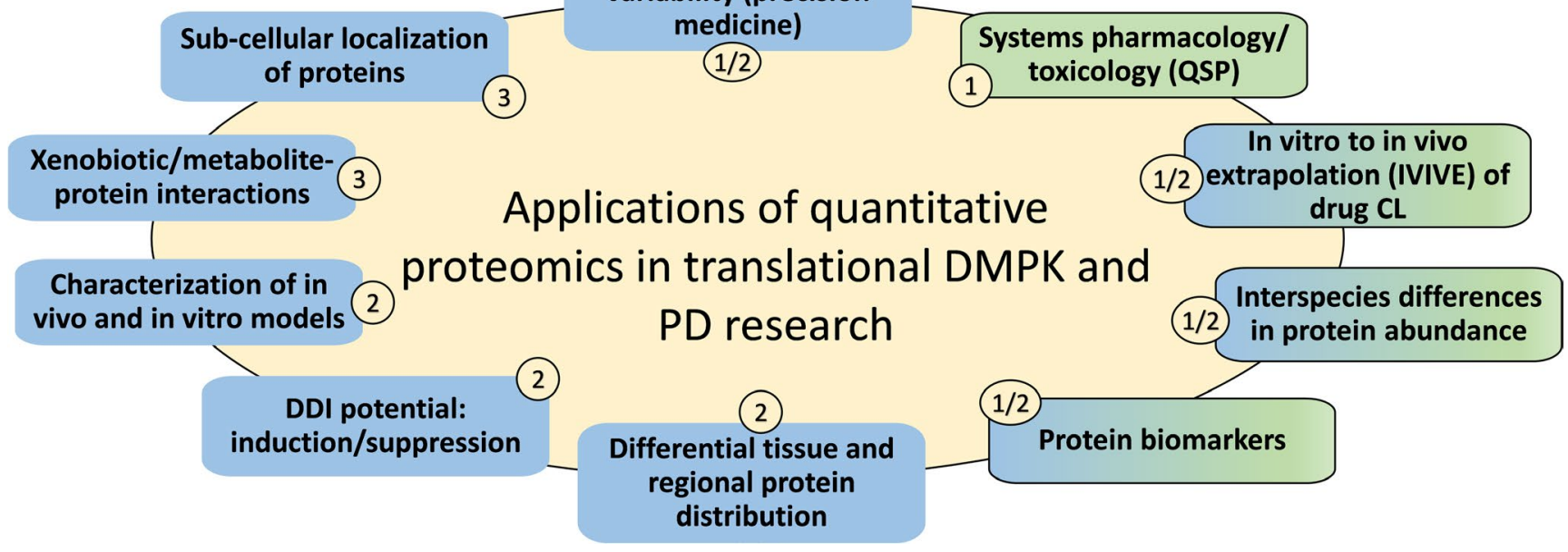

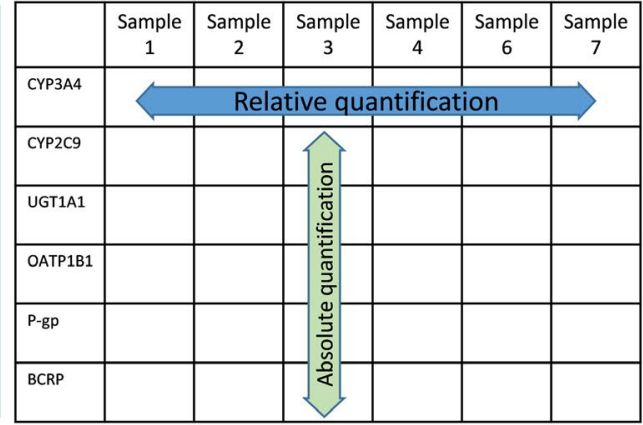

Absolute Quantification

- Comparison of the same and different proteins between samples

- Use of a reference or calibrator

Figure 4 Applications of relative and absolute proteomic quantification in translational pharmacology research. Top. "Absolute" quantification is needed when comparing multiple proteins in a sample (protein network analysis), whereas "relative" quantification works equally well if a single protein is compared across samples (effect of polymorphism, age, disease, etc.). Bottom. Quantitative proteomics applications in translational pharmacology research. The labels (1, 2, and 3) on different applications indicate the requirement for tier 1, tier 2, and tier 3 assays (see Table 3). The colors on the applications refer to suitability of "absolute" (green), "relative" (blue), or both types of proteomic measurements for the application.

(Table 4). This approach has been successfully used for IVIVE of transporter-based clearance of drugs. ${ }^{2,3}$

\section{CONCLUSION}

The attendees of the Cambridge Workshop had the vision that with the increasing utility and popularity of quantitative proteomics, there is an urgent need to consolidate experiences of various groups working in the field and to create a structure of collective wisdom where consensus can be achieved. The workshop was successful in conveying the critical need of optimized and harmonized practices for quantitative proteomics in translational pharmacology. The current report is a culmination of efforts and contributions by the attendees and the authors are grateful to all participants on whose behalf this White Paper was prepared. Although this White Paper addresses several issues related to different methodological and application themes, various unresolved points are outlined, which the organizers aim to address through more coordinated research and participation in similar future workshops.

\section{SUPPORTING INFORMATION}

Supplementary information accompanies this paper on the Clinical Pharmacology \& Therapeutics website (www.cpt-journal.com).
Table 4 Theoretical example illustrating the process of generating consistent cross-laboratory IVIVE scaling factors with consistent (but suboptimal) protein digestion efficiency

\begin{tabular}{lccc}
\hline & Lab 1 & Lab 2 & Lab 3 \\
\hline $\mathrm{K}_{\mathrm{m}}(\mu \mathrm{M})$ & 10 & 10 & 10 \\
\hline $\begin{array}{l}\mathrm{V}_{\max } \text { (cell line) (pmol/min/ } \\
\mathrm{mg} \text { protein) }\end{array}$ & 100 & 100 & 100 \\
\hline $\begin{array}{l}\text { Protein abundance in cell } \\
\text { line (pmol/mg protein) [A] }\end{array}$ & 25 & 50 & 75 \\
$\begin{array}{l}\text { Protein abundance in tissue } \\
\text { (pmol/mg protein) [B] }\end{array}$ & 5 & 10 & 15 \\
$\begin{array}{l}\text { IVIVE scaling factor } \\
{[\mathrm{SF}=\mathrm{B} / \mathrm{A}]}\end{array}$ & 0.2 & 0.2 & 0.2 \\
$\begin{array}{l}\text { Clearance (in vivo) }=\left[\mathrm{V}_{\max } /\right. \\
\mathrm{K}_{\mathrm{m}}\end{array}$ & 2 & 2 & 2
\end{tabular}

$\left.\mathrm{K}_{\mathrm{m}}\right]_{\text {cell line }} \times \mathrm{SF}$

IVIVE, in vitro-in vivo extrapolation; $\mathrm{K}_{\mathrm{m}}$, protein affinity for the drug; $\mathrm{V}_{\max }$, maximal rate of metabolism.

Table S1. Recommended definitions of terms and techniques used in quantitative proteomics. 


\section{ACKNOWLEDGMENTS}

The authors would like to thank the International Society for the Study of Xenobiotics and Takeda Pharmaceuticals for organizing and hosting the workshop and other industrial sponsors (Certara, BiolVT, Solvo, BristolMyers Squibb, and Genentech) who facilitated the event by generous donations. They also acknowledge the contributions made by all the workshop attendees, in general, and the following view point speakers, in particular, for insightful comments during the discussions: Abdul Basit (University of Washington), Anna Vildhede (AstraZeneca), Buyun Chen (Genentech), Evita van de Steeg (TNO), Fatemeh Akhlaghi (University of Rhode Island), Haojie Zhu (University of Michigan), John Fallon (University of North Carolina), Katsuaki Ito (University of North Carolina), Manthena Varma (Pfizer), Martyn Howard (University of Manchester), Matthew Harwood (Certara), Michael Wang (University of Kansas), Oliver Poetz (University of Tubingen), Rick Greupink (Radboud University), Ryota Kikuchi (Abbvie), Stefan Oswald (University of Greifswald), Sumio Ohtsuki (Kumamoto University), and Vineet Kumar (University of Washington). Buyun Chen, Christine Wegler, Magnus Ölander, Niklas Handin, and Oliver Poetz are acknowledged for critical review of the manuscript.

\section{FUNDING}

J.D.U. and B.P. were supported in part by UWRAPT funded by Gilead Sciences Inc., Genentech, Merck \& Co., Biogen, Takeda Pharmaceutical Company, and Pfizer. J.D.U. and B.P. were also supported by National Institutes of Health (NIH) grant numbers P01 DA032507 and R01 HD081299. B.P. is also supported by PRINCE program funded by Genentech, Gilead, and Merck. A.R.H. and B.A. acknowledge support from CAPKR consortium funded by Janssen, Certara, Merck, Takeda, MSD, Eli Lilly, and Genentech.

\section{CONFLICT OF INTEREST}

The authors declared no competing interests for this work.

(c) 2019 The Authors Clinical Pharmacology \& Therapeutics

๑) 2019 American Society for Clinical Pharmacology and Therapeutics

1. Zineh, I. Quantitative systems pharmacology: a regulatory perspective on translation. CPT Pharmacometrics Syst. Pharmacol. 8, 336-339 (2019).

2. Kumar, V. et al. The importance of incorporating OCT2 plasma membrane expression and membrane potential in IVIVE of metformin renal secretory clearance. Drug Metab. Dispos. 46, 1441-1445 (2018).

3. Ishida, K., Ullah, M., Tóth, B., Juhasz, V. \& Unadkat, J.D. Successful prediction of in vivo hepatobiliary clearances and hepatic concentrations of rosuvastatin using sandwich-cultured rat hepatocytes, transporter-expressing cell lines, and quantitative proteomics. Drug Metab. Dispos. 46, 66-74 (2018).

4. Bi, Y. et al. Quantitative assessment of the contribution of sodium-dependent taurocholate co-transporting polypeptide (NTCP) to the hepatic uptake of rosuvastatin, pitavastatin and fluvastatin. Biopharm. Drug Dispos. 34, 452-461 (2013).

5. Vildhede, A. et al. Comparison of proteomic quantification approaches for hepatic drug transporters: multiplexed global quantitation correlates with targeted proteomic quantitation. Drug Metab. Dispos. 46, 692-696 (2018).

6. Vildhede, A. et al. Hepatic uptake of atorvastatin: influence of variability in transporter expression on uptake clearance and drug-drug interactions. Drug Metab. Dispos. 42, 1210-1218 (2014).

7. Doki, K. et al. Implications of intercorrelation between hepatic CYP3A4-CYP2C8 enzymes for the evaluation of drug-drug interactions: a case study with repaglinide. Br. J. Clin. Pharmacol. 84 972-986 (2018).

8. Prasad, B. et al. Ontogeny of hepatic drug transporters as quantified by LC-MS/MS proteomics. Clin. Pharmacol. Ther. 100, 362-370 (2016).

9. Bhatt, D.K. et al. Age- and genotype-dependent variability in the protein abundance and activity of six major uridine diphosphate-glucuronosyltransferases in human liver. Clin. Pharmacol. Ther. 105, 131-141 (2019).

10. Boberg, M. et al. Age-dependent absolute abundance of hepatic carboxylesterases (CES1 and CES2) by LC-MS/MS proteomics: application to PBPK modeling of oseltamivir in vivo pharmacokinetics in infants. Drug Metab. Dispos. 45, 216-223 (2017).

11. van Groen, B.D. et al. Proteomics of human liver membrane transporters: a focus on fetuses and newborn infants. Eur. J. Pharm. Sci. 124, 217-227 (2018).

12. Prasad, B. et al. Abundance of phase 1 and 2 drug-metabolizing enzymes in alcoholic and hepatitis $C$ cirrhotic livers: a quantitative targeted proteomics study. Drug Metab. Dispos. 46, 943-952 (2018).

13. Wang, L. et al. Transporter expression in liver tissue from subjects with alcoholic or hepatitis $C$ cirrhosis quantified by targeted quantitative proteomics. Drug Metab. Dispos. 44, 1752-1758 (2016).

14. Peng, K., Bacon, J., Zheng, M., Guo, Y. \& Wang, M.Z. Ethnic variability in the expression of hepatic drug transporters: absolute quantification by an optimized targeted quantitative proteomic approach. Drug Metab. Dispos. 43, 1045-1055 (2015).

15. Kawakami, H. et al. Simultaneous absolute quantification of 11 cytochrome P450 isoforms in human liver microsomes by liquid chromatography tandem mass spectrometry with in silico target peptide selection. J. Pharm. Sci. 100, 341-352 (2011).

16. Prasad, B. et al. Interindividual variability in hepatic organic anion-transporting polypeptides and P-glycoprotein (ABCB1) protein expression: quantification by liquid chromatography tandem mass spectroscopy and influence of genotype, age, and sex. Drug Metab. Dispos. 42, 78-88 (2014).

17. Wegler, C. et al. Variability in mass spectrometry-based quantification of clinically relevant drug transporters and drug metabolizing enzymes. Mol. Pharm. 14, 3142-3151 (2017).

18. Kamiie, J. et al. Quantitative atlas of membrane transporter proteins: development and application of a highly sensitive simultaneous LC/MS/MS method combined with novel in-silico peptide selection criteria. Pharm. Res. 25, 1469-1483 (2008).

19. Fallon, J.K., Neubert, H., Hyland, R., Goosen, T.C. \& Smith, P.C. Targeted quantitative proteomics for the analysis of 14 UGT1As and -2Bs in human liver using NanoUPLC-MS/MS with selected reaction monitoring. J. Proteome Res. 12, 4402-4413 (2013).

20. Whiteaker, J.R. et al. CPTAC Assay Portal: a repository of targeted proteomic assays. Nat. Methods 11, 703-704 (2014).

21. Lanucara, F., Holman, S.W., Gray, C.J. \& Eyers, C.E. The power of ion mobility-mass spectrometry for structural characterization and the study of conformational dynamics. Nat. Chem. $\mathbf{6}$, 281-294 (2014).

22. Achour, B., Al Feteisi, H., Lanucara, F., Rostami-Hodjegan, A. \& Barber, J. Global proteomic analysis of human liver microsomes: rapid characterization and quantification of hepatic drug-metabolizing enzymes. Drug Metab. Dispos. 45, 666-675 (2017).

23. Olszowy, P.P., Burns, A. \& Ciborowski, P.S. Pressure-assisted sample preparation for proteomic analysis. Anal. Biochem. $\mathbf{4 3 8}$, 67-72 (2013)

24. Sprung, R.W. et al. Equivalence of protein inventories obtained from formalin-fixed paraffin-embedded and frozen tissue in multidimensional liquid chromatography-tandem mass spectrometry shotgun proteomic analysis. Mol. Cell Proteom. 8, 1988-1998 (2009).

25. Ostasiewicz, P., Zielinska, D.F., Mann, M. \& Wiśniewski, J.R. Proteome, phosphoproteome, and $\mathrm{N}$-glycoproteome are quantitatively preserved in formalin-fixed paraffin-embedded tissue and analyzable by high-resolution mass spectrometry. J. Proteome Res. 9, 3688-3700 (2010).

26. Wiśniewski, J.R. et al. Extensive quantitative remodeling of the proteome between normal colon tissue and adenocarcinoma. Mol. Syst. Biol. 8, 611 (2012)

27. Kennedy, J.J. et al. Optimized protocol for quantitative multiple reaction monitoring-based proteomic analysis of formalin-fixed, paraffin-embedded tissues. J. Proteome Res. 15, 2717-2728 (2016). 
28. Knights, K.M. et al. Scaling factors for the in vitro-in vivo extrapolation (IV-IVE) of renal drug and xenobiotic glucuronidation clearance. Br. J. Clin. Pharmacol. 81, 1153-1164 (2016).

29. Drozdzik, M. et al. Protein abundance of clinically relevant multidrug transporters along the entire length of the human intestine. Mol. Pharm. 11, 3547-3555 (2014).

30. Drozdzik, M. et al. Protein abundance of clinically relevant drug-metabolizing enzymes in the human liver and intestine: a comparative analysis in paired tissue specimens. Clin. Pharmacol. Ther. 104, 515-524 (2018).

31. Vildhede, A., Wiśniewski, J.R., Norén, A., Karlgren, M. \& Artursson, P. Comparative proteomic analysis of human liver tissue and isolated hepatocytes with a focus on proteins determining drug exposure. J. Proteome Res. 14, 3305-3314 (2015).

32. Wiśniewski, J.R., Vildhede, A., Norén, A. \& Artursson, P. In-depth quantitative analysis and comparison of the human hepatocyte and hepatoma cell line HepG2 proteomes. J. Proteom. 136, 234-247 (2016).

33. Ohtsuki, S., Kikkawa, T., Hori, S. \& Terasaki, T. Modulation and compensation of the mRNA expression of energy related transporters in the brain of glucose transporter 1-deficient mice. Biol. Pharm. Bull. 29, 1587-1591 (2006).

34. Gröer, C. et al. Absolute protein quantification of clinically relevant cytochrome P450 enzymes and UDPglucuronosyltransferases by mass spectrometry-based targeted proteomics. J. Pharm. Biomed. Anal. 100, 393-401 (2014).

35. Harwood, M.D., Russell, M.R., Neuhoff, S., Warhurst, G. \& Rostami-Hodjegan, A. Lost in centrifugation: accounting for transporter protein losses in quantitative targeted absolute proteomics. Drug Metab. Dispos. 42, 1766-1772 (2014).

36. Wiśniewski, J.R., Wegler, C. \& Artursson, P. Subcellular fractionation of human liver reveals limits in global proteomic quantification from isolated fractions. Anal. Biochem. 509, 82-88 (2016).

37. Xu, M. et al. Targeted LC-MS/MS proteomics-based strategy to characterize in vitro models used in drug metabolism and transport studies. Anal. Chem. 90, 11873-11882 (2018).

38. Ölander, M. et al. A simple approach for restoration of differentiation and function in cryopreserved human hepatocytes. Arch. Toxicol. 93, 819-829 (2018).

39. Chun, S.-E. et al. The N-terminal region of organic anion transporting polypeptide 1B3 (OATP1B3) plays an essential role in regulating its plasma membrane trafficking. Biochem. Pharmacol. 131, 98-105 (2017).

40. Kumar, V., Nguyen, T.B., Tóth, B., Juhasz, V. \& Unadkat, J.D. Optimization and application of a biotinylation method for quantification of plasma membrane expression of transporters in cells. AAPS J. 19, 1377-1386 (2017).

41. Kumar, V. et al. A comparison of total and plasma membrane abundance of transporters in suspended, plated, sandwich-cultured human hepatocytes versus human liver tissue using quantitative targeted proteomics and cell surface biotinylation. Drug Metab. Dispos. 47, 350-357 (2019).

42. Weiß, F. et al. Indirect protein quantification of drug-transforming enzymes using peptide group-specific immunoaffinity enrichment and mass spectrometry. Sci. Rep. 5, 8759 (2015).

43. Razavi, M., Leigh Anderson, N., Pope, M.E., Yip, R. \& Pearson, T.W. High precision quantification of human plasma proteins using the automated SISCAPA Immuno-MS workflow. N. Biotechnol. 33, 494-502 (2016).

44. Wiśniewski, J.R. \& Mann, M. Consecutive proteolytic digestion in an enzyme reactor increases depth of proteomic and phosphoproteomic analysis. Anal. Chem. 84, 2631-2637 (2012).

45. Wiśniewski, J.R., Wegler, C. \& Artursson, P. Multiple-enzymedigestion strategy improves accuracy and sensitivity of labeland standard-free absolute quantification to a level that is achievable by analysis with stable isotope-labeled standard spiking. J. Proteome Res. 18, 217-224 (2018).

46. Wis̈niewski, J. R. \& Gaugaz, F. Z. Fast and sensitive total protein and peptide assays for proteomic analysis. Anal. Chem. 87, 4110-4116 (2015).
47. Sielaff, M. et al. Evaluation of FASP, SP3, and iST protocols for proteomic sample preparation in the low microgram range. J. Proteome Res. 16, 4060-4072 (2017).

48. Howard, M., Achour, B., Al-Majdoub, Z.M., Rostami-Hodjegan, A. \& Barber, J. GASP and FASP are complementary for LC-MS/MS proteomic analysis of drug-metabolizing enzymes and transporters in pig liver. Proteomics 18, e1800200 (2018).

49. Kulak, N.A., Pichler, G., Paron, I., Nagaraj, N. \& Mann, M. Minimal, encapsulated proteomic-sample processing applied to copy-number estimation in eukaryotic cells. Nat. Methods $\mathbf{1 1}$, 319-324 (2014).

50. Moggridge, S., Sorensen, P.H., Morin, G.B. \& Hughes, C.S. Extending the compatibility of the SP3 paramagnetic bead processing approach for proteomics. J. Proteome Res. 17, 17301740 (2018).

51. Kulak, N.A., Geyer, P.E. \& Mann, M. Loss-less nano-fractionator for high sensitivity. High coverage proteomics. Mol. Cell Proteom 16, 694-705 (2017)

52. Al-Majdoub, Z.M., Carroll, K.M., Gaskell, S.J. \& Barber, J. Quantification of the proteins of the bacterial ribosome using QconCAT technology. J. Proteome Res. 13, 1211-1222 (2014)

53. Gygi, S.P. et al. Quantitative analysis of complex protein mixtures using isotope-coded affinity tags. Nat. Biotechnol. 17, 994-999 (1999).

54. Ross, P.L. et al. Multiplexed protein quantitation in Saccharomyces cerevisiae using amine-reactive isobaric tagging reagents. Mol. Cell Proteom. 3, 1154-1169 (2004).

55. Ong, S.-E. et al. Stable isotope labeling by amino acids in cell culture, SILAC, as a simple and accurate approach to expression proteomics. Mol. Cell Proteom. 1, 376-386 (2002).

56. Prasad, B. \& Unadkat, J.D. Optimized approaches for quantification of drug transporters in tissues and cells by MRM proteomics. AAPS J. 16, 634-648 (2014).

57. Cox, J. \& Mann, M. Quantitative, high-resolution proteomics for data-driven systems biology. Annu. Rev. Biochem. 80, 273-299 (2011).

58. Ludwig, C. et al. Data-independent acquisition-based SWATH-MS for quantitative proteomics: a tutorial. Mol. Syst. Biol. 14, e8126 (2018).

59. Schubert, O.T., Röst, H.L., Collins, B.C., Rosenberger, G. \& Aebersold, R. Quantitative proteomics: challenges and opportunities in basic and applied research. Nat. Protoc. 12, 12891294 (2017).

60. Smith, B.J., Martins-de-Souza, D. \& Fioramonte, M. A guide to mass spectrometry-based quantitative proteomics. Methods Mol. Biol. 1916, 3-39 (2019).

61. Carr, S.A. et al. Targeted peptide measurements in biology and medicine: best practices for mass spectrometry-based assay development using a fit-for-purpose approach. Mol. Cell Proteom. 13, 907-917 (2014).

62. Bilbao, A. et al. Processing strategies and software solutions for data-independent acquisition in mass spectrometry. Proteomics 15, 964-980 (2015)

63. Meier, F., Geyer, P.E., Virreira Winter, S., Cox, J. \& Mann, M. BoxCar acquisition method enables single-shot proteomics at a depth of 10,000 proteins in 100 minutes. Nat. Methods $\mathbf{1 5}$ 440-448 (2018).

64. Zhu, X., Chen, Y. \& Subramanian, R. Comparison of information-dependent acquisition, SWATH, and MS(All) techniques in metabolite identification study employing ultrahigh-performance liquid chromatography-quadrupole time-of-flight mass spectrometry. Anal. Chem. 86, 1202-1209 (2014).

65. Wiśniewski, J.R. Label-free and standard-free absolute quantitative proteomics using the "total protein" and "proteomic ruler" approaches. Methods Enzymol. 585, 49-60 (2017).

66. Wiśniewski, J.R., Hein, M.Y., Cox, J. \& Mann, M. A "proteomic ruler" for protein copy number and concentration estimation without spike-in standards. Mol. Cell Proteom. 13, 3497-3506 (2014).

67. Chen, B. et al. Strategies of drug transporter quantitation by LC-MS: importance of peptide selection and digestion efficiency. AAPS J. 19, 1469-1478 (2017) 
68. Badee, J., Achour, B., Rostami-Hodjegan, A. \& Galetin, A. Metaanalysis of expression of hepatic organic anion-transporting polypeptide (OATP) transporters in cellular systems relative to human liver tissue. Drug Metab. Dispos. 43, 424-432 (2015).

69. Achour, B., Barber, J. \& Rostami-Hodjegan, A. Expression of hepatic drug-metabolizing cytochrome P450 enzymes and their intercorrelations: a meta-analysis. Drug Metab. Dispos. 42, 1349-1356 (2014).

70. Harwood, M.D. et al. In vitro-in vivo extrapolation scaling factors for intestinal P-glycoprotein and breast cancer resistance protein: Part I: a cross-laboratory comparison of transporter-protein abundances and relative expression factors in human intestine and Caco-2 cells. Drug Metab. Dispos. 44, 297-307 (2016).

71. Shi, J. et al. Determining allele-specific protein expression (ASPE) using a novel quantitative concatamer based proteomics method. J. Proteome Res. 17, 3606-3612 (2018).

72. Achour, B., Rostami-Hodjegan, A. \& Barber, J. Response to 'Determining Allele-Specific Protein Expression (ASPE) using a novel quantitative concatamer based proteomics method'. J. Proteome Res. 18, 574 (2019).

73. Al Feteisi, H., Achour, B., Barber, J. \& Rostami-Hodjegan, A. Choice of LC-MS methods for the absolute quantification of drug-metabolizing enzymes and transporters in human tissue: a comparative cost analysis. AAPS J. 17, 438-446 (2015).

74. Ong, S.-E. \& Mann, M. A practical recipe for stable isotope labeling by amino acids in cell culture (SILAC). Nat. Protoc. 1, 2650-2660 (2006).

75. Macleod, A.K. et al. A targeted in vivo SILAC approach for quantification of drug metabolism enzymes: regulation by the constitutive androstane receptor. J. Proteome Res. 13, 866-874 (2014).

76. Geiger, T., Cox, J., Ostasiewicz, P., Wisniewski, J.R. \& Mann, M. Super-SILAC mix for quantitative proteomics of human tumor tissue. Nat. Methods 7, 383-385 (2010).

77. Achour, B., Russell, M.R., Barber, J. \& Rostami-Hodjegan, A. Simultaneous quantification of the abundance of several cytochrome P450 and uridine 5'-diphospho-glucuronosyltransferase enzymes in human liver microsomes using multiplexed targeted proteomics. Drug Metab. Dispos. 42, 500-510 (2014).

78. Russell, M.R. et al. Alternative fusion protein strategies to express recalcitrant QconCAT proteins for quantitative proteomics of human drug metabolizing enzymes and transporters.

J. Proteome Res. 12, 5934-5942 (2013).

79. Achour, B. et al. Ten years of QconCATs: application of multiplexed quantification to small medically relevant proteomes. Int. J. Mass Spectrom. 391, 93-104 (2015).

80. Cheung, C.S.F., Anderson, K.W., Wang, M. \& Turko, I.V. Natural flanking sequences for peptides included in a quantification concatamer internal standard. Anal. Chem. 87, 1097-1102 (2015).

81. Achour, B. et al. Data generated by quantitative liquid chromatography-mass spectrometry proteomics are only the start and not the endpoint: optimization of quantitative concatemer-based measurement of hepatic uridine-59-diphosphate-glucuronosyltransferase enzymes with ref. Drug Metab. Dispos. 46, 805-812 (2018).

82. US Food and Drug Administration (FDA). Bioanalytical method validation, guidance for industry <https://www.fda.gov/downl oads/drugs/guidances/ucm070107.pdf> (2018). Accessed April 29, 2019.

83. Validation of Analytical Procedures: Text and Methodology Q2(R1). International Conference on Harmonisation of Technical Requirements for Registration of Pharmaceuticals for Human Use <https://www.ich.org/fileadmin/Public_Web_Site/
ICH_Products/Guidelines/Quality/Q2_R1/Step4/Q2_R1__Guide line.pdf> (2005). Accessed May 22, 2019.

84. MacLean, B. et al. Skyline: an open source document editor for creating and analyzing targeted proteomics experiments. Bioinformatics 26, 966-968 (2010).

85. Sharma, V. et al. Panorama: a targeted proteomics knowledge base. J. Proteome Res. 13, 4205-4210 (2014).

86. Reiter, L. et al. mProphet: automated data processing and statistical validation for large-scale SRM experiments. Nat. Methods $\mathbf{8}$, 430-435 (2011).

87. Silva, J.C. Absolute quantification of proteins by LCMSE: a virtue of parallel MS acquisition. Mol. Cell Proteom. 5, 144-156 (2005)

88. Rappsilber, J. Large-scale proteomic analysis of the human spliceosome. Genome Res. 12, 1231-1245 (2002).

89. Ishihama, Y. et al. Exponentially modified protein abundance index (emPAl) for estimation of absolute protein amount in proteomics by the number of sequenced peptides per protein. Mol. Cell Proteom. 4, 1265-1272 (2005).

90. Tommi, V., Suomi, T. \& Elo, L.L. A comprehensive evaluation of popular proteomics software workflows for label-free proteome quantification and imputation. Brief. Bioinform. 19, 1344-1355 (2018)

91. Achour, B. et al. Quantitative characterization of major hepatic UDPglucuronosyltransferase (UGT) enzymes in human liver microsomes: comparison of two proteomic methods and correlation with catalytic activity. Drug Metab. Dispos. 45, 1102-1112 (2017).

92. Bhatt, D.K. \& Prasad, B. Critical issues and optimized practices in quantification of protein abundance level to determine interindividual variability in DMET proteins by LC-MS/MS proteomics. Clin. Pharmacol. Ther. 103, 619-630 (2018).

93. Ternent, T. et al. How to submit MS proteomics data to ProteomeXchange via the PRIDE database. Proteomics 14, 2233-2241 (2014).

94. Abbatiello, S. et al. New guidelines for publication of manuscripts describing development and application of targeted mass spectrometry measurements of peptides and proteins. Mol. Cell Proteom. 16, 327-328 (2017).

95. Prasad, B., Vrana, M., Mehrotra, A., Johnson, K. \& Bhatt, D.K. The promises of quantitative proteomics in precision medicine. J. Pharm. Sci. 106, 738-744 (2017).

96. Zientek, M.A. \& Youdim, K. Reaction phenotyping: advances in the experimental strategies used to characterize the contribution of drug-metabolizing enzymes. Drug Metab. Dispos. 43, 163-181 (2015).

97. van der Graaf, P.H. Pharmacometrics and/or systems pharmacology. CPT Pharmacometrics Syst. Pharmacol. 8, 331-332 (2019). https://doi.org/10.1002/psp4.12376.

98. Bowman, C.M., Okochi, H. \& Benet, L.Z. The presence of a transporter-induced protein binding shift: a new explanation for protein-facilitated uptake and improvement for in vitro-in vivo extrapolation. Drug Metab. Dispos. 47, 358-363 (2019).

99. Kim, S.-J., Lee, K.-R., Miyauchi, S. \& Sugiyama, Y. Extrapolation of in vivo hepatic clearance from in vitro uptake clearance by suspended human hepatocytes for anionic drugs with high binding to human albumin: improvement of in vitro-to-in vivo extrapolation by considering the 'albumin-mediated' hepatic $\mathrm{U}$. Drug Metab. Dispos. 47, 94-103 (2019).

100. Harwood, M. D. et al. In vitro-in vivo extrapolation scaling factors for intestinal P-glycoprotein and breast cancer resistance protein: part II. The impact of cross-laboratory variations of intestinal transporter relative expression factors on predicted drug disposition. Drug Metab. Dispos. 44, 476-480 (2016). 